\title{
Insights into Crystal Structure and Diffusion of Biphasic $\mathrm{Na}_{2} \mathrm{Zn}_{2} \mathrm{TeO}_{6}$
}

\author{
Xinyu Li,* Federico Bianchini, Julia Wind, Christine Pettersen, David S. Wragg, Ponniah Vajeeston,
} and Helmer Fjellvåg*

Cite This: ACS Appl. Mater. Interfaces 2020, 12, 28188-28198

Read Online

ACCESS |

山ll Metrics \& More

Article Recommendations

Supporting Information

ABSTRACT: The layered oxide $\mathrm{Na}_{2} \mathrm{Zn}_{2} \mathrm{TeO}_{6}$ is a fast $\mathrm{Na}^{+}$ion conductor and a suitable candidate for application as a solid-state electrolyte. We present a detailed study on how synthesis temperature and $\mathrm{Na}$-content affect the crystal structure and thus the $\mathrm{Na}^{+}$ion conductivity of $\mathrm{Na}_{2} \mathrm{Zn}_{2} \mathrm{TeO}_{6}$. Furthermore, we report for the first time an $\mathrm{O}^{\prime} 3$-type phase for $\mathrm{Na}_{2} \mathrm{Zn}_{2} \mathrm{TeO}_{6}$. At a synthesis temperature of $900{ }^{\circ} \mathrm{C}$, we obtain a pure P2-type phase, providing peak performance in $\mathrm{Na}^{+}$ion conductivity. Synthesis temperatures lower than $900{ }^{\circ} \mathrm{C}$ produce a series of mixed P2 and $\mathrm{O}^{\prime} 3$-type phases. The $\mathrm{O}^{\prime} 3$ structure can only be obtained as a pure phase by substituting $\mathrm{Li}$ on the $\mathrm{Zn}$-sites to increase the $\mathrm{Na}$-content. Thorough analysis of synchrotron data combined with computa-

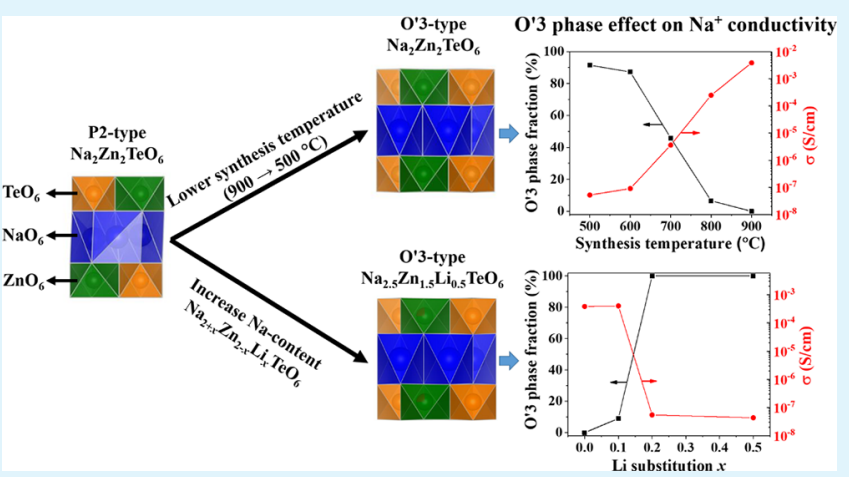
tional modeling indicates that $\mathrm{Li}$ enters the $\mathrm{Zn}$ sites and, consequently, the amount of $\mathrm{Na}$ in the structure increases to balance the charge according to the formula $\mathrm{Na}_{2+x} \mathrm{Zn}_{2-x} \mathrm{Li}_{x} \mathrm{TeO}_{6}(x$ $=0.2-0.5)$. Impedance spectroscopy and computational modeling confirm that reducing the amount of the $\mathrm{O}^{\prime} 3$-type phase enhances the $\mathrm{Na}^{+}$ion mobility.

KEYWORDS: $\mathrm{Na}_{2} \mathrm{Zn}_{2} \mathrm{TeO}_{6}, \mathrm{P} 2$-type, $\mathrm{O}^{\prime} 3$-type, $\mathrm{Na}^{+}$ion conductor, layered structure

\section{INTRODUCTION}

Owing to the high natural abundance and (consequently) low cost of sodium, combined with possibility of using electrode materials with lower financial and environmental cost, sodiumion batteries (SIBs) are emerging as a real alternative to lithiumion batteries. ${ }^{1-4}$ The alkali elements, $\mathrm{Li}$ and $\mathrm{Na}$, have similar chemical and physical properties. The current Li-based battery technology can thus be readily converted to sodium-ion batteries. With regard to safety, it is desirable to replace the traditional organic liquid electrolytes with a solid-state equivalent, preventing the hazards of leakage and flammability. ${ }^{5}$ Solid-state electrolytes (SSEs) may also allow the development of molten sodium based batteries and cathodes with higher operational voltages to increase energy density. The main obstacles to the development of viable SIB SSEs are their relatively poor $\mathrm{Na}^{+}$ion conductivity, and poor interface compatibility with commercial electrodes. ${ }^{6}$ Some of the most suitable candidates investigated so far include $\mathrm{Na}_{3} \mathrm{Zr}_{2} \mathrm{Si}_{2} \mathrm{PO}_{12}{ }^{7-9} \mathrm{Na}-\beta$-alumina, ${ }^{10,11}$ and $\mathrm{Na}_{3} \mathrm{PS}_{4}{ }^{12}$

Another well-known family of $\mathrm{Na}$ superionic conductors is the layered oxides $\mathrm{Na}_{x} \mathrm{MO}_{2}(0<x \leq 1)$, where $M$ represents metal or metalloid elements. Early investigations of these layered oxides focused on cathode materials such as $\mathrm{Na}_{x} \mathrm{CoO}_{2}$, as described by Delmas and Hagenmuller. ${ }^{13-15}$ Their crystal structures are composed of edge-sharing $\mathrm{MO}_{6}$ octahedra forming $\left(\mathrm{MO}_{2}\right)_{n}$ layers with $\mathrm{Na}^{+}$ions intercalated. These layered oxides are classified according to the coordination geometry of $\mathrm{Na}^{+}$ions $(\mathrm{P}$ and $\mathrm{O}$, indicating prismatic and octahedral $\mathrm{Na}$ coordination, respectively) and the number of positionally distinct $\left(\mathrm{MO}_{2}\right)_{n}$ layers. ${ }^{15}$ The most commonly observed structural types are P2 and $\mathrm{O} 3$, which have been extensively studied as cathode materials due to their superior electrochemical properties. ${ }^{16-19}$

O3 and P2-type structures crystallize in rhombohedral (space group $R \overline{3} m)^{20,21}$ or hexagonal crystal systems (space group $P 6_{3}$ / $m m c$ for $\mathrm{Na}_{0.67} \mathrm{CoO}_{2}$ and $\mathrm{Pb}_{3} 22$ for $\left.\mathrm{Na}_{2} \mathrm{Zn}_{2} \mathrm{TeO}_{6}\right)$, ${ }^{21-24}$ respectively. Distorted modifications, often reported in literature, are labeled using an additional prime symbol. Some examples are the $\mathrm{O}^{\prime} 3$-type compounds $\mathrm{NaMnO}_{2}$ and $\mathrm{Na}_{2} \mathrm{Cu}_{2} \mathrm{TeO}_{6}$ (space group $\mathrm{C} 2 / m$ ), ${ }^{25,26} \mathrm{P}^{\prime}$ 3-type $\mathrm{Na}_{x} \mathrm{CoO}_{2}$, $(0.6<x<0.67 \text {, space group } \mathrm{C} 2 / \mathrm{m})^{21}$ and the $\mathrm{P}^{\prime} 2$-type $\mathrm{Na}_{x} \mathrm{MnO}_{2},(x=2 / 3$, space group $\mathrm{Cmcm}) .{ }^{27}$ Different, distinct phases can be obtained by tuning the sodium content and controlling the synthesis conditions, e.g. precursors, temperature and conditions for heat treatment and heating/cooling rate. ${ }^{16,21,23,24}$ The O3-type phase is stable when Na-content is high (i.e., $x$ is close to 1 ), while the P2-type structure becomes

Received: March 30, 2020

Accepted: June 2, 2020

Published: June 2, 2020 
more favorable when $x$ is in the range $0.3-0.7 .^{21,28}$ The low Nacontent $(x<1)$ in $\mathrm{P} 2$-type $\mathrm{Na}_{x} \mathrm{MO}_{2}$ causes a strong repulsive interaction between the oxygen anions, increasing the $\mathrm{MO}_{2}$ interlayer separation. ${ }^{15}$ Early studies on $\mathrm{Na}_{x} \mathrm{CoO}_{2}(0.55<x<$ 0.88 ) demonstrated that the P2-type phase is usually obtained in the temperature range $650-900{ }^{\circ} \mathrm{C}$, while $\mathrm{O}^{\prime} 3$ or $\mathrm{P}^{\prime} 3$ are obtained at lower temperature $\left(500-550{ }^{\circ} \mathrm{C}\right) .^{21,29,30}$

A new family of P2-type layered tellurates $\mathrm{Na}_{2} \mathrm{M}_{2} \mathrm{TeO}_{6}(M=$ $\mathrm{Zn}, \mathrm{Co}, \mathrm{Ni}, \mathrm{Mg})$ with high $\mathrm{Na}^{+}$ion conductivity $\left(\sim 10^{-5} \mathrm{~S} / \mathrm{cm}\right.$ at room temperature) has recently been reported by Evstigneeva and coauthors. ${ }^{23}$ These are structurally related to P2-type $\mathrm{Na}_{x} \mathrm{CoO}_{2}$ with complete $\mathrm{M}^{2+} / \mathrm{Te}^{6+}$ ordering in each $\left(\mathrm{MO}_{2}\right)_{n}$ layers. ${ }^{31}$ Various P2-type layered structures were described in two distinct hexagonal space groups: $P 6_{3} / \mathrm{mcm}$ for $\mathrm{Na}_{2} \mathrm{Ni}_{2} \mathrm{TeO}_{6},{ }^{32}$ and $\mathrm{P6}_{3} 22$ for $\mathrm{Na}_{2} M_{2} \mathrm{TeO}_{6}(M=\mathrm{Zn}, \mathrm{Co})^{24,33}$ as well for the majority phase of $\mathrm{Na}_{2} \mathrm{Mg}_{2} \mathrm{TeO}_{6} \cdot{ }^{34}$ These two structure types are related by an in-plane shift of one of the $\left(\mathrm{M}_{2} \mathrm{Te}\right)_{n}$ layers. In our recent work, we have shown that these two types of stacking coexist in $\mathrm{Na}_{2} \mathrm{Zn}_{2} \mathrm{TeO}_{6}$ (NZTO). ${ }^{35}$ The materials with $M=\mathrm{Zn}$ and $\mathrm{Mg}$ are considered as ideal candidates for application as solid-state electrolytes. The $\mathrm{Na}^{+}$ion conductivity and electrochemical stability against cathode and $\mathrm{Na}$ metal for P2-type $\mathrm{Na}_{2} \mathrm{M}_{2} \mathrm{TeO}_{6}(M=\mathrm{Zn}, \mathrm{Mg})$ were systematically studied by $\mathrm{Li}$ et al. ${ }^{24,34,36}$ Both these phases exhibit high $\mathrm{Na}^{+}$ion conductivity of $10^{-4} \mathrm{~S} / \mathrm{cm}$ at room temperature and excellent electrochemical stability with wide electrochemical window $(4.0-4.2 \mathrm{~V})$. It was further found that the $\mathrm{Na}^{+}$ion conductivity in NZTO can be increased to $10^{-3} \mathrm{~S} /$ $\mathrm{cm}$ upon $\mathrm{Ga}^{3+}$ substitution for $\mathrm{Zn}^{2+}$ which increases the amount of $\mathrm{Na}^{+}$vacancies. This is consistent with results from molecular dynamics studies of $\mathrm{Na}_{2} \mathrm{Ni}_{2} \mathrm{TeO}_{6}{ }^{37-39}$ A more recent study showed that $\mathrm{Ca}^{2+}$ substitution for $\mathrm{Zn}^{2+}$ can increase the $\mathrm{Na}^{+}$ion conductivity as a result of expansion of the intralayer distance. ${ }^{40}$ In a very recent report, Dubey et al. ${ }^{41}$ investigated the structural properties and $\mathrm{Na}^{+}$ion mobility of $\mathrm{Na}_{2} \mathrm{M}_{2} \mathrm{TeO}_{6}(\mathrm{M}=\mathrm{Mg} / \mathrm{Ni}$ and $\mathrm{Mg} / \mathrm{Zn}$ ) and $\mathrm{Na}_{2} \mathrm{Mg}_{2} \mathrm{TeO}_{6}$. They showed that samples containing $\mathrm{Ni}$ or $\mathrm{Zn}$ exhibit a better phase purity than that obtained for samples of $\mathrm{Na}_{2} \mathrm{Mg}_{2} \mathrm{TeO}_{6}$. The coexistence of $\mathrm{Mg}$ and $\mathrm{Ni}$ or $\mathrm{Zn}$ in $\mathrm{Na}_{2} \mathrm{M}_{2} \mathrm{TeO}_{6}$ also reduces the grain boundary resistance compared to that of $\mathrm{Na}_{2} \mathrm{Mg}_{2} \mathrm{TeO}_{6}$, thus increasing the $\mathrm{Na}^{+}$ion mobility.

We have systematically explored the impact of synthesis conditions and $\mathrm{Na}$-content on the structural properties of NZTO and $\mathrm{Na}^{+}$ion mobility. Our focus on NZTO is motivated by its high $\mathrm{Na}^{+}$ion mobility compared to other P2-type Nabased tellurates. Below in Section 3.1.1 we present the effect of synthesis temperature on the structural properties of NZTO, and prove the existence of an $\mathrm{O}^{\prime} 3$-type phase with powder X-ray diffraction data, supported by DFT calculations. We furthermore discuss Li-substitution and the preferred crystallographic site of $\mathrm{a} \mathrm{Li}^{+}$ion and the consequent formation of a single $\mathrm{O}^{\prime} 3$ type phase in Section 3.1.2. Finally, impedance spectroscopy results for all the samples are reported in Section 3.2. Here, we also calculate the macroscopic conductivity and associated activation energies. These reveal that the $\mathrm{O}^{\prime} 3$-type phase is detrimental to $\mathrm{Na}^{+}$ion mobility. This combination of methods offers great insight into the properties of the layered materials, and helps to advance the state-of-the-art design of SSE materials.

\section{METHODS}

2.1. Synthesis. Samples of NZTO and Li-substituted $\mathrm{Na}_{2+x} \mathrm{Zn}_{1-x} \mathrm{Li}_{x} \mathrm{TeO}_{6}(x=0.1,0.2,0.5)$ were synthesized via conventional solid-state methods. $\mathrm{Na}_{2} \mathrm{CO}_{3}$ (Sigma-Aldrich, 99.5\%), $\mathrm{Li}_{2} \mathrm{CO}_{3}$
(Sigma-Aldrich, 99.997\%), $\mathrm{ZnO}$ (Sigma-Aldrich, 99.99\%), and $\mathrm{TeO}_{2}$ (Sigma-Aldrich, 99\%) were used as precursors. $\mathrm{ZnO}, \mathrm{Na}_{2} \mathrm{CO}_{3}$, and $\mathrm{Li}_{2} \mathrm{CO}_{3}$ were preheated at $150{ }^{\circ} \mathrm{C}$ for $6 \mathrm{~h}$ in a muffle furnace to remove possible surface water. Stoichiometric amounts of the respective precursors were ball-milled for $30 \mathrm{~min}$. An excess of $10 \mathrm{wt} \% \mathrm{Na}_{2} \mathrm{CO}_{3}$ and 10 wt $\% \mathrm{Li}_{2} \mathrm{CO}_{3}$ were added to compensate for $\mathrm{Na}$ and $\mathrm{Li}$ evaporation at elevated temperatures. For NZTO samples, batches of the mixed precursors were calcined at six different temperatures: 500, $600,700,800,900$, and $950^{\circ} \mathrm{C}$ for $6 \mathrm{~h}$. The samples produced will be referred to as NZTO500, NZTO600, NZTO700, NZTO800, NZTO900, and NZTO950, where the number denotes the synthesis temperature. Synthesis at higher temperature (e.g., $950{ }^{\circ} \mathrm{C}$ ) resulted in a number of dense impurity phases. The mixed precursor batches for $\mathrm{Li}$ substituted samples were calcined at $900{ }^{\circ} \mathrm{C}$ for $6 \mathrm{~h}$. After the first calcination step, the powders were ball milled again individually for $1 \mathrm{~h}$ and cold pressed into $10 \mathrm{~mm}$ diameter pellets. The pellets were covered with their mother powders and placed in covered alumina crucibles to be sintered. The five NZTO samples were sintered at their original synthesis temperatures for another $15 \mathrm{~h}$. Li-substituted samples were sintered at $900{ }^{\circ} \mathrm{C}$ for $15 \mathrm{~h}$. The heating and cooling rates for all calcination and sintering processes were $5{ }^{\circ} \mathrm{C} / \mathrm{min}$. All as-synthesized samples were stored in a glovebox to avoid air contact before characterizations.

2.2. Data Collection and Analysis. Initial sample characterization was done by powder X-ray diffraction (PXRD) on a Bruker D8 Discover diffractometer in Bragg-Brentano mode with a LynxEye detector and $\mathrm{Cu} \mathrm{K} \alpha_{1}$ radiation $(\lambda=1.5406 \AA$ ) selected by a $\mathrm{Ge}(111)$ monochromator at the Norwegian national resource center for X-ray diffraction and scattering (RECX).

In situ variable temperature PXRD measurements were performed on a Bruker D8 A25 powder diffractometer (RECX lab) with focusing mirror optics and LynxEye XE high energy detector on a mixture of NZTO precursors $\left(\mathrm{Na}_{2} \mathrm{CO}_{3}, \mathrm{ZnO}\right.$, and $\left.\mathrm{TeO}_{2}\right)$. Data were collected with Mo K $\alpha$ radiation $\left(\lambda \alpha_{1}=0.7093 \AA, \lambda \alpha_{2}=0.7136 \AA\right)$ during heating from $30-900{ }^{\circ} \mathrm{C}$ and cooling back to $30^{\circ} \mathrm{C}$ with a ramp rate of $5{ }^{\circ} \mathrm{C} /$ min in an Anton Paar HTK 1200 high temperature chamber.

Room temperature synchrotron powder X-ray diffraction (SPXRD) patterns were collected at BM31, one of the Swiss-Norwegian Beamlines (SNBL) at the European Synchrotron (ESRF). Diffraction profiles for NZTO samples were collected using a Pilatus $2 \mathrm{M} \mathrm{CdTe}$ detector $^{42}$ and diffraction profiles for Li-substituted samples were collected using a Dexela 2923 2D CMOS detector. ${ }^{43}$ Samples were sealed into $0.5 \mathrm{~mm}$ thin-wall glass capillaries. The wavelengths $(\lambda=$ $0.319089 \AA$ for the Pilatus $2 \mathrm{M} \mathrm{CdTe}$ detector and $0.49426 \AA$ for the Dexela 2923 2D CMOS detector) were calibrated against a NIST $\mathrm{LaB}_{6}$ standard. Diffraction patterns were recorded over an angular range of 2.5 to $25^{\circ}$ for NZTO samples and 2.5 to $35^{\circ}$ for Li-substituted samples, respectively. Rietveld refinements against PXRD data were performed using TOPAS V5.0. ${ }^{44}$ In Rietveld refinements, the background was fitted using 9-13 term Chebychev polynomials. Unit cell dimensions and scale factors were refined for each data set. Site occupancies and atomic coordinates were refined and details are described in the respective sections and the Supporting Information (SI). A thermal displacement parameter for each atom-type was determined from the refinement against SPXRD data of NZTO900. The obtained thermal displacement parameters were fixed for the refinements against SPXRD data of NZTO800-500 and $\mathrm{Na}_{2+x} \mathrm{Zn}_{2-x} \mathrm{Li}_{x} \mathrm{TeO}_{6}(x=0.1,0.2,0.5)$. Due to the short wavelengths used in the SPXRD measurements, no absorption corrections were necessary. Ball-and-stick and coordination polyhedra models were rendered with VESTA. ${ }^{45}$

Elemental analyses of as-synthesized $\mathrm{Na}_{2+x} \mathrm{Zn}_{1-x} \mathrm{Li}_{x} \mathrm{TeO}_{6}(x=0,0.1$, $0.2,0.5)$ were performed by inductively coupled plasma (ICP) on a Bruker Aurora Elite equipped with Cetac ASX-250 autosampler and an ESI oneFAST sample introduction system.

2.3. Computational Modeling. First principles atomistic calculations based on Density Functional Theory (DFT) are performed using the Vienna Ab initio Simulation Package (VASP). ${ }^{46-49}$ All calculations are computed within the general gradient approximation, using the Perdew, Burke, and Ernzerhof form of the exchange and correlation functional. ${ }^{50}$ Integrals over the Brillouin zone are computed 
Table 1. Selected Intralayer Distances $(\AA)$ and Bond Lengths $(\AA)$ in the P2 and $\mathrm{O}^{\prime}$ 3-Type Phases Based on Experimental and Theoretical Results

\begin{tabular}{lll} 
structures & \multicolumn{1}{c}{ label } & $d_{z}\left(\mathrm{NaO}_{6}\right)$ \\
$\mathrm{O}^{\prime} 3$ & $2 h$ & $3.21-3.24$ \\
$\mathrm{O}^{\prime} 3$ & $1 h 1 d$ & $3.24-3.27$ \\
$\mathrm{O}^{\prime} 3(\mathrm{Exp})$ & $\mathrm{NZTO} 700$ & $3.16-3.29$ \\
$\mathrm{P} 2$ & $1 f 1 g$ & $3.29-3.47$ \\
$\mathrm{P} 2$ & $2 g$ & $3.29-3.34$ \\
$\mathrm{P} 2($ Exp $)$ & NZTO700 & 3.42
\end{tabular}

$d_{\mathrm{O}-\mathrm{O}}\left(\mathrm{NaO}_{6}\right)$
$3.56-3.75$
$3.64-3.84$
$3.58-3.73$
$3.34-3.61$
$3.31-3.39$
3.42

3.42

$d_{z}\left(\mathrm{Zn}_{2} \mathrm{TeO}_{6}\right)$
$2.11-2.15$
$2.12-2.16$
$2.25-2.37$
$2.03-2.21$
$2.14-2.18$
2.20
$d_{\mathrm{O}-\mathrm{O}}\left(\mathrm{Zn}_{2} \mathrm{TeO}_{6}\right)$ $2.70-3.03$

$2.70-3.03$
$2.72-3.03$

$2.89-2.93$

$2.71-3.08$

$2.74-3.03$

$2.68-2.93$ on $\Gamma$-centered Monkhorst-Pack grids with a resolution of $0.3 \AA^{-1}$. The Fermi-level smearing of electron states is introduced according to the Methfessel-Paxton method ${ }^{51}$ with a $0.2 \mathrm{eV}$ broadening width. With these settings, a $500 \mathrm{eV}$ kinetic energy cutoff for the plane wave expansion is found to produce total energies converged within $5 \mathrm{meV}$ per formula unit. All the considered structural minima are obtained from geometrical optimization of configurations from experimental inputs. These relaxations are computed first at fixed cell and then allowing for the optimization of the lattice degrees of freedom. The total energies are then calculated as a function of volume by imposing a diagonal deformation with $1 \%$ increments. These structural optimizations are performed using the conjugate gradient algorithm with a force convergence threshold of $10^{-2} \mathrm{eV} / \AA$, while the energy convergence threshold of the self-consistent field (SCF) calculation is set to $10^{-4} \mathrm{eV}$. The projection operators are evaluated in real-space for computational efficiency.

The stability of the P2 and O'3 NZTO phases is verified by calculating the elastic tensor and the vibrational density of states. The former is computed by imposing six lattice distortions and fitting the strain-stress relationship. This is calculated for rigid ions and adjusted by accounting for internal relaxation by inversion of the Hessian matrix. ${ }^{52}$ For these calculations, the convergence threshold of the SCF calculation is set to $10^{-6} \mathrm{eV}$. The phonon density of states is calculated using the finite differences method as implemented in the phonopy software. ${ }^{53}$ These calculations are performed on suitably large supercell models, using an atomic displacement of 0.01 Å along both positive and negative directions. These calculations require a different setup to accurately evaluate the Hellmann-Feynman forces associated with these displacements: an additional support fast Fourier transform grid, eight times denser than the standard one, is used for the evaluation of the augmentation charges. The projection operators are evaluated in reciprocal space, despite the large size of the systems, and the convergence threshold of a SCF calculations is set to $10^{-8} \mathrm{eV}$.

In this work, we considered a selection of point defects in the NZTO structure: substitutional $(\mathrm{Li})$ and interstitial $(\mathrm{Na})$ impurity atoms are necessary to describe the Li-doping mechanism of NZTO, while Na vacancies are used to model the diffusion path. As in the case of the vibrational density of states, these systems require large supercell models to suppress the interaction between a defect and its periodic image. Well-converged results are obtained using a $2 \times 1 \times 2$ model for the $\mathrm{O}^{\prime} 3$ cell in Table 1 . Similarly, we make use of a $2 \times 1 \times 1$ model for the P2-type structure or a $2 \times 2 \times 1$ when the reconstruction of the $\mathrm{Na}$ sublattice is not considered. All these supercell models contain 88 atoms, corresponding to 8 formula units.

Calculations involving impurity atoms are performed using the same set of parameters as for structural relaxation. The activation energy associated with $\mathrm{Na}^{+}$ion mobility is calculated using the Nudged Elastic Band (NEB) method. ${ }^{54}$ The diffusion mechanism is assumed to be a single vacancy hop to a neighboring Na-site. Four replicas of the system are introduced to model the minimum energy transition path, initially assumed to be linear. The structural optimization of these intermediate images is carried out using the conjugate gradient algorithm with a force convergence threshold of $40 \mathrm{meV} / \AA . \AA$.

Additional tools used in this work include the Atomic Simulation Environment (ASE) code, ${ }^{55}$ used for converting format of input/ output files and data analysis, the QUIP package and its python interface quippy ${ }^{56}$ used for computing interatomic distances and generating the input files for the NEB calculations. The space groups are identified using the FINDSYM software. ${ }^{57}$

2.4. Impedance Spectroscopy. The $\mathrm{Na}^{+}$ion conductivity of NZTO samples and Li-substituted samples was measured as a function of temperature by electrochemical impedance spectroscopy ${ }^{24}$ using a Probostat (NorECs AS) sample holder in a frequency range of 1 to $10^{7}$ $\mathrm{Hz}$ with a $10 \mathrm{mV}$ AC amplitude. For each composition, two parallel pellet samples with different thicknesses were adapted for the measurement to check measurement consistency. All the pellet samples were preheated at $150{ }^{\circ} \mathrm{C}$ for $6 \mathrm{~h}$ in a muffle furnace to remove surface water. The pellets ( $10 \mathrm{~mm}$ in diameter and $0.56-2.13 \mathrm{~mm}$ in thickness) were coated with silver paste (SPI Supplies Co.) on both full faces and dried at $60^{\circ} \mathrm{C}$ in a drying oven for $30 \mathrm{~min}$. Pt wires were then attached to the two faces of the pellets. Impedance measurements were taken in air at temperatures from 28 to $211{ }^{\circ} \mathrm{C}$. The data were fitted with equivalent circuits and analyzed using Zview2 (Scribner, Inc.).

\section{RESULTS AND DISCUSSION}

3.1. Synthesis and Structural Characterization. 3.1.1. Biphasic NZTO. The phase purity of the as-synthesized NZTO samples was evaluated using PXRD, and the results are presented in Figure 1. NZTO900 is indexed in space group

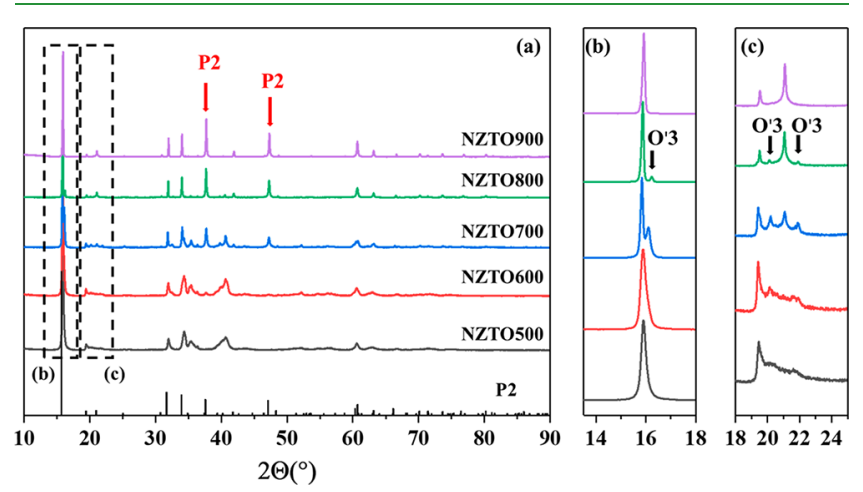

Figure 1. (a) PXRD patterns of NZTO samples synthesized at 900, $800,700,600,500{ }^{\circ} \mathrm{C}(\lambda=1.5406 \AA)$; (b) enlargement of the strongest peaks in a $2 \theta$ range of $13.5-18^{\circ}$; (c) enlargement of peaks in a $2 \theta$ range of $18-25^{\circ}$. Red and black arrows indicate characteristic peaks for P2type and $\mathrm{O}^{\prime} 3$-type phases, respectively.

$\mathrm{P}_{3} 22$ as a single $\mathrm{P} 2$-type phase, consistent with previous studies (cf. Figure S1 and Table S1)..$^{23,24,35,40}$ At lower synthesis temperatures, the amount of P2-type phase gradually decreases and other phases appear. Yet, the main phase in the PXRD patterns of NZTO800 and NZTO700 matches well with the P2type phase. Several additional peaks, not belonging to the P2type phase, are observed as indicated by black arrows in Figure 1. In the case of NZTO600 and NZTO500, the amount of the P2type phase (indicated by red arrows in Figures 1 and S2) decreases while the intensity of the additional peaks increases. The existence of these additional diffraction peaks has been reported previously by Evstigneeva et al. ${ }^{23}$ for $\mathrm{Na}_{2} \mathrm{Mg}_{2} \mathrm{TeO}_{6}$. 

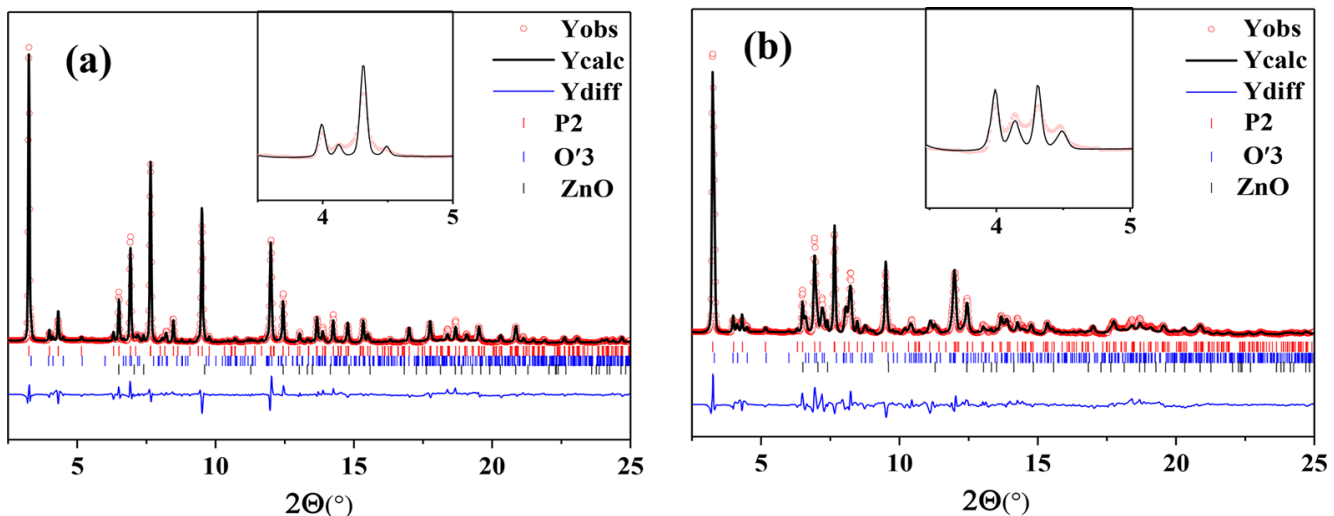

Figure 2. Rietveld refinements against SPXRD data of (a) NZTO800 and (b) NZTO700, $\lambda=0.319089 \AA$ (inset: enlargement of $2 \theta$ range of 3.5 to $\left.5.0^{\circ}\right)$. The experimental pattern is shown in red, calculated pattern in black, the difference between experimental and calculated curves in blue. Bragg positions of $\mathrm{P} 2, \mathrm{O}^{\prime} 3$-type phases and impurity $\mathrm{ZnO}$ are in red, blue, and black, respectively.

The structure of the additional phase was, however, not resolved. Since this feature seems to be intrinsic to these layered oxides, it is highly desirable to resolve its structure and identify its effect on the properties of the material and in particular on the $\mathrm{Na}^{+}$ion mobility. The literature suggests ${ }^{58-60}$ that an O3-type structure is a prime candidate, as phase transformations between these two modifications are often observed. To the best of our knowledge, the existence of O3-type NZTO has never previously been reported.

The regular O3-type (space group $R \overline{3} \mathrm{~m}$ ) and the distorted $\mathrm{O}^{\prime} 3$ modification (space group $\mathrm{C} 2 / \mathrm{m}$ ), constructed based on $\mathrm{Na}_{2} \mathrm{Cu}_{2} \mathrm{TeO}_{6}{ }^{25}$ as $\mathrm{O}^{\prime} 3$ model_1, were tested to see if they gave a reasonable fit to the $\overline{S P X R D}$ data, but the outcome was poor (see SI Figures S3 and S4; Tables S2 and S3).

Seibel et al. ${ }^{61}$ suggest that $\mathrm{Na}_{3} \mathrm{Ni}_{2} \mathrm{BiO}_{6}$ crystallizes as an $\mathrm{O}^{\prime} 3$ type phase with a partial antisite disorder between the $\mathrm{Ni}$ - and Bi-sites. Based on this, we constructed a second $\mathrm{O}^{\prime} 3$-type structural model (denoted $\mathrm{O}^{\prime} 3$ _model_2) by replacing Ni with $\mathrm{Zn}$ and $\mathrm{Bi}$ with $\mathrm{Te}$, and adjusting the $\mathrm{Na}$ occupancy to its stoichiometric value. In this structural model, $\mathrm{Na}$ occupies two distinct Wyckoff site types: $2 d$ and $4 h$, while $\mathrm{Zn}$ occupies a $4 g$ site and Te occupies a $2 a$ site. Rietveld refinements using this model against the SPXRD patterns of NZTO700 and NZTO800 are presented in Figure 2, showing acceptable fits. Crystallographic information for the involved $\mathrm{P} 2$ and O'3-type phases is summarized in Tables S4 and S5. Note that the still imperfect fit of the diffraction peaks in the $2 \theta$-range $3.5-5.0^{\circ}$ is due to the presence of stacking faults in the P2-type phase, ${ }^{35}$ or possibly a P2/O'3-type composite as described by Guo et al. ${ }^{62}$

For NZTO the effects of antisite disorder within the layers or between the layers (stacking faults) are hard to distinguish from one another. ${ }^{35,63,64}$ For NZTO700, the Na site occupancies for the two distinct sites, as well as the $\mathrm{Zn} / \mathrm{Te}$ mixed site occupancies were refined independently. Constraints were applied to fix the total occupancy for each atom-type to the corresponding stoichiometric values. The fraction of $\mathrm{Zn}$ atoms on the Te site and vice versa was constrained so as to maintain the 2:1 Zn:Te ratio. For NZTO700 the refined occupancies for the $\mathrm{O}^{\prime} 3$-type phase show that some $1.15 \%$ of the Te atoms are located on the $\mathrm{Zn}$ sites. SPXRD is sensitive to this low level of antisite disorder due to large $\mathrm{X}$-ray scattering contrast between $\mathrm{Zn}(Z=30)$ and $\mathrm{Te}(Z=52)$. The $\mathrm{Zn} / \mathrm{Te}$ mixed occupancies in the $\mathrm{O}^{\prime} 3$-type phase in NZTO800 were fixed to the values derived for NZTO700 (NZTO800 contains only 6\% weight of O'3-type phase).
Refinements for NZTO600 and NZTO500 (Figure S5) confirm that the $\mathrm{O}^{\prime} 3$-type phase dominates $\left(\sim 87 \% \mathrm{O}^{\prime} 3\right.$ in NZTO600 and $\sim 91 \% \mathrm{O}^{\prime} 3$ in NZTO500, see Table S6). However, the crystallinity of these samples is not sufficiently good for deriving structural details. Annealing NZTO500 at 500 ${ }^{\circ} \mathrm{C}$ for 7 days did not improve the crystallinity (see Figure S6). This indicates that a pure O'3-type NZTO with high crystallinity is rather hard to be synthesized using solid-state methods. It could be possible to obtain such pure O'3-type NZTO using other synthesis methods, e.g., precipitation or solgel method.

To gain a deeper insight into the phase evolution of NZTO, we studied the product formation by means of in situ with PXRD (cf. Figure S7) during heating from $30-900{ }^{\circ} \mathrm{C}$. Due to the poor crystallinity of the sample, only qualitative information could be extracted. Three distinct transitions occur during heating. At around $250{ }^{\circ} \mathrm{C} \mathrm{Na}_{2} \mathrm{CO}_{3}$ starts to decompose and reacts with $\mathrm{TeO}_{2}$ to form $\mathrm{Na}_{2} \mathrm{TeO}_{4}$. This is stable until $\sim 350{ }^{\circ} \mathrm{C}$, when the $\mathrm{O}^{\prime} 3$-type phase starts to form. On further increasing the temperature, the P2-type phase starts to appear at $\sim 500^{\circ} \mathrm{C}$ and coexists with small amount of $\mathrm{O}^{\prime} 3$-type phase up to $\sim 900{ }^{\circ} \mathrm{C}$. The O'3-type phase did not completely disappear toward 900 ${ }^{\circ} \mathrm{C}$, which may be due to the phase transition kinetics. ${ }^{23}$ No changes in the PXRD pattern were observed on subsequent cooling from 900 to $30^{\circ} \mathrm{C}$, indicating no phase conversion from $\mathrm{O}^{\prime} 3$ to $\mathrm{P} 2$-type phase. This is in agreement with our previous results that show no signs of a $\mathrm{P} 2$ to $\mathrm{O}^{\prime} 3$-type phase transformation on prolonged annealing of NZTO900 at 600 ${ }^{\circ} \mathrm{C}$ for 7 days. ${ }^{35}$

The unit cells of the monoclinic $\mathrm{O}^{\prime} 3$ and hexagonal P2-type phases are closely related: $a_{\mathrm{mon}}$ and $b_{\text {mon }}$ correspond to $a_{\text {hex }}$ and $\sqrt{3} a_{\text {hex }}$ (cf. Figure S8), respectively. The comparison of the refined lattice parameters for the $\mathrm{P} 2$ and $\mathrm{O}^{\prime} 3$-type phases shows that $a_{\text {mon }}, b_{\text {mon }}$ are similar to $a_{\text {hex }}, \sqrt{ } 3 a_{\text {hex }}$ for the biphasic NZTO samples. The $c$ axes of the two structure types are not coincident and it is therefore not meaningful to provide a direct comparison. Moreover, the unit cells contain different numbers of $\mathrm{Zn}_{2} \mathrm{TeO}_{6}$ layers ( 2 and 1 for $\mathrm{P} 2$ and $\mathrm{O}^{\prime} 3$, respectively). A better comparison is made by considering the distances between adjacent oxygen layers along the normal to the $\mathrm{Zn}_{2} \mathrm{TeO}_{6}$ layers (i.e., the $c$ axis direction of the P2-type structure, cf. Figure 3 ). These values are reported in Table 1 . The distances between the octahedral $\mathrm{Zn}_{2} \mathrm{TeO}_{6}$ layers, labeled $\mathrm{d}_{z}\left(\mathrm{NaO}_{6}\right)$ and indicated in Figure 3, are 3.42 and 3.16-3.29 $\AA$ for $\mathrm{P} 2$ and $\mathrm{O}^{\prime} 3$, respectively. The larger spacing in the P2 case is expected, as the closest 


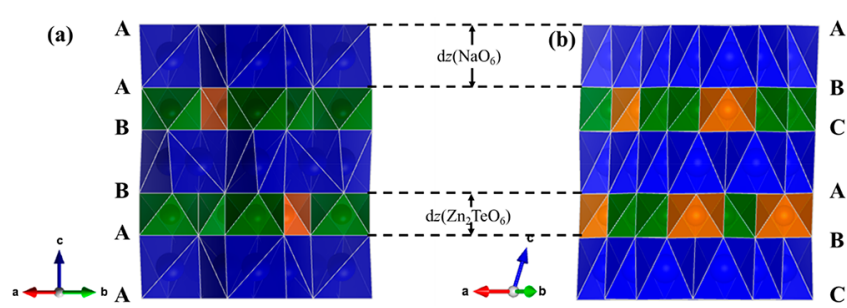

Figure 3. Crystal structures of $\mathrm{P} 2$ (a) and $\mathrm{O}^{\prime} 3$-type NZTO (b). The separations $\mathrm{d}_{z}\left(\mathrm{NaO}_{6}\right)$ and $\mathrm{d}_{z}\left(\mathrm{Zn}_{2} \mathrm{TeO}_{6}\right)$ are defined as the perpendicular distance between the two parallel oxygen layers based on an average $\mathrm{z}$ coordinate of $\mathrm{Na}$ and $\mathrm{Zn} / \mathrm{Te}$ atoms, respectively. The $\mathrm{NaO}_{6}, \mathrm{ZnO}_{6}$, and $\mathrm{TeO}_{6}$ polyhedra are shown in blue, green and brown, respectively. Labels $\mathrm{A}, \mathrm{B}$, and $\mathrm{C}$ denote distinct oxygen layers.

oxygen atoms in adjacent layers share the same $(x, y)$ coordinates. This explains why the P2-type phase becomes dominant only at elevated temperatures. This can be better understood by considering the $\mathrm{O}-\mathrm{O}$ distances instead of the layer separation. These are 3.42 and 3.58-3.73 $\AA$ for P2 and $\mathrm{O}^{\prime} 3$, respectively. The shorter $\mathrm{O}-\mathrm{O}$ distance in the $\mathrm{P} 2$-type phase causes additional repulsion between layers. This reduces the thickness of $\mathrm{Zn}_{2} \mathrm{TeO}_{6}$ octahedral layers ( 2.20 vs $2.25-2.37 \AA$ in the $\mathrm{O}^{\prime} 3$ case).

The first principles calculations verify the experimental results by showing the stability of the O'3-type phase. It is important to find the correct structural model for both the P2 and O'3-type phases. Due to the partial occupancy of the sodium sites, this operation is not trivial. ${ }^{65}$ Within the P2-type structure, six possible $\mathrm{Na}$ sites are available per formula unit, only two of which occupied in the specific case of NZTO. All $\mathrm{Na}^{+}$ions at these positions form $\mathrm{NaO}_{6}$ coordination polyhedra of triangular prismatic shape. These prisms can share either their edges ( $g$ type sites; multiplicity 3 per formula unit) or faces ( $f$, a-type sites; multiplicity 2, 1 respectively per formula unit) with the $\mathrm{TeO}_{6}$ and $\mathrm{ZnO}_{6}$ octahedral groups. These positions are indicated in Figure 4(c) with sphere models of distinct color. From structural considerations (Pauling's third rule), one would expect that face-sharing is not favorable, however, this does not match experimental evidence. It is indeed found, by means of $a b$ initio calculations, that $\mathrm{Na}^{+}-\mathrm{Na}^{+}$repulsion plays a nonnegligible role in determining the equilibrium configuration, enforcing a nonhexagonal reconstruction of the Na sublattice. ${ }^{65}$ Analogously to our previous works of NZTO, ${ }^{35,65}$ we label the distinct models used for DFT calculations with the Wyckoff symbols associated with the fully occupied sites and the number of such sites filled per formula unit (not the multiplicity of the sites). With this definition, a P2 structure containing Na only at $g$ sites is labeled $2 g$. Note that the multiplicity of $g$ sites is 3 per formula unit and, therefore, one of them is unoccupied, resulting in honeycomb-like ordering of the sodium sublattice. Similarly, the $\mathrm{O}^{\prime} 3$ model labeled $1 d 1 \mathrm{~h}$ has $1 \mathrm{Na}$ ion at a $d$ site and one at an $h$ site, while the remaining $h$ site is unoccupied. These types of structures are necessary for atomistic modeling, as DFT or related methods cannot describe the partial occupation of Wyckoff sites. Moreover, these models provide information regarding the bonding of single sites and, therefore, facilitate the understanding of these materials at the atomic scale. The aforementioned nonhexagonal reconstruction of the $\mathrm{Na}$ sublattice is obtained by filling simultaneously a $g$-type site and a nonadjacent $f$-type site $(1 g 1 f)$. The better stability of such a reconstruction is evident from the energy-volume curves in Figure 4(a). A more detailed discussion on $\mathrm{Na}$ sites and the (a)

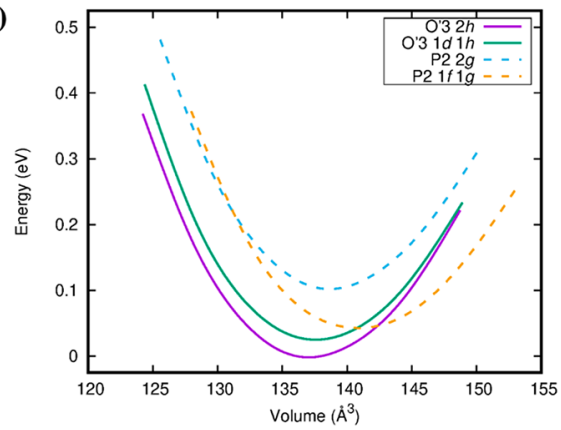

(b)

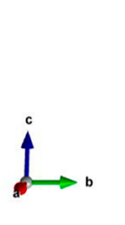

(d)
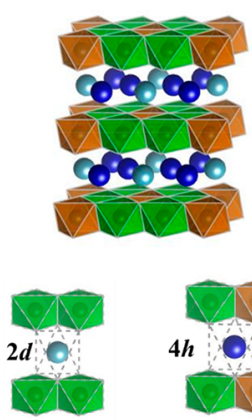

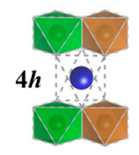

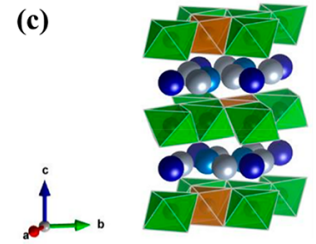

(e)

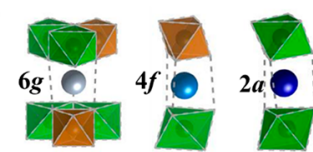

Figure 4. Energy/volume curves for the most stable P2 (dash line) and $\mathrm{O}^{\prime} 3$ (solid line) configurations (a). The configurations are labeled accordingly to the occupation of Na sites within a layer. Structural model for the $\mathrm{O}^{\prime} 3$ (b) and P2-type (c) structures. The $\mathrm{ZnO}_{6}$ and $\mathrm{TeO}_{6}$ polyhedra are shown in green and brown, respectively. Polyhedral environments of respective $\mathrm{Na}$ sites in $\mathrm{O}^{\prime} 3$ (d) and P2-type (e) structures. All the possible $\mathrm{Na}$ sites and the respective multiplicities are indicated.

associated energetics is provided in our previous publications. $^{35,65}$ In the $\mathrm{O}^{\prime} 3$-type phase, $2 \mathrm{Na}$ sites ( $4 h$ and $2 d$ ) per formula unit are available, as indicated in Figure 4(b). The interatomic distances between $\mathrm{Na}^{+}$ions and neighboring $\mathrm{Zn}^{2+}$ and $\mathrm{Te}^{6+}$ are reported in Table S7. From these values, it is clear that these ions are nearly equivalent when only nearest neighbors are considered. The second shell, however, is different, as the $d$-type site is coordinated by four $\mathrm{Zn}^{2+}$ ions and the $h$-type site by two $\mathrm{Zn}^{2+}$ and two $\mathrm{Te}^{6+}$ ions. This difference is small but significant, as revealed by the energy/ volume curves for the $\mathrm{O}^{\prime} 3$-type phase in Figure 4(a). The configuration presenting a honeycomb-ordered sublattice of $\mathrm{Na}^{+}$ions at the $h$-type sites is found to be energetically more favorable. Only this configuration will be considered further below. The equilibrium lattice constants for each of the considered structures are reported in Table 2. The interlayer distances are reported in Table 1 and the fitting parameters to the Murnaghan equation of states can be found in Table S8. The energetics reported in Figure S8 clearly indicate the O'3-type phase as more stable modification. In this structure, face-sharing of coordination polyhedra is completely avoided, while the distances between $\mathrm{O}^{2-}$ ions in adjacent layers is maximized. The formation of a P2-type phase seems to be solely associated with the supercell reconstruction of the $\mathrm{Na}$ sublattice or, more in general, with disordered sublattice models in which both $g$ - and $f$-type sites are simultaneously (partially) occupied. The presence of an $\mathrm{O}^{\prime} 3$-type phase is therefore expected, especially when the local environment presents $\mathrm{Na}$ excess or deficiency.

3.1.2. Li-Substituted NZTO: $\mathrm{Na}_{2+x} \mathrm{Zn}_{2-x} \mathrm{Li}_{x} \mathrm{TeO}_{6}(x=0.1,0.2$, 0.5). We explored the stability range of the P2-type phase by varying the Na-content in NZTO. As discussed in the 
Table 2. Unit Cell Dimensions for a Selection of Theoretical and Experimental Configurations

\begin{tabular}{|c|c|c|c|c|c|c|c|c|}
\hline \multirow[b]{2}{*}{ structure } & \multirow[b]{2}{*}{ space group } & \multirow[b]{2}{*}{ label } & \multicolumn{6}{|c|}{ lattice parameters } \\
\hline & & & $a(\AA)$ & $b(\AA)$ & $c(\AA)$ & $\alpha(\operatorname{deg})$ & $\beta(\operatorname{deg})$ & $\gamma(\operatorname{deg})$ \\
\hline $\mathrm{O}^{\prime} 3$ & $\mathrm{C} 2 / \mathrm{m}$ & $2 h$ & 5.481 & 9.124 & 5.811 & 90 & 110.48 & 90 \\
\hline $\mathrm{O}^{\prime} 3$ & & $1 h 1 d$ & 5.326 & 9.356 & 5.727 & 90 & 107.22 & 90 \\
\hline $\mathrm{O}^{\prime} 3$ & & NZTO700 & 5.321 & 9.183 & 5.861 & 90 & 109.13 & 90 \\
\hline $\mathrm{P} 2$ & $\mathrm{P}_{3} 22$ & $1 f 1 g$ & 5.338 & 9.254 & 11.353 & 90 & 90 & 90 \\
\hline $\mathrm{P} 2$ & & $2 g$ & 5.322 & 5.381 & 11.054 & 90 & 90 & 119.64 \\
\hline $\mathrm{P} 2$ & & NZTO900 & 5.288 & 5.288 & 11.239 & 90 & 90 & 120 \\
\hline
\end{tabular}

Introduction, the formation of an O3-type phase is usually associated with a large $\mathrm{Na}$-content. For NZTO, the composition can be tuned by $\mathrm{Li}$-substitution. $\mathrm{Li}^{+}$has a similar ionic radius $(0.76 \AA)$ to $\mathrm{Zn}^{2+}(0.74 \AA)$. Such a substitution on the $\mathrm{Zn}$-site would increase the $\mathrm{Na}$-content according to the formula $\mathrm{Na}_{2+x} \mathrm{Zn}_{2-x} \mathrm{Li}_{x} \mathrm{TeO}_{6}$. We prepared three different samples with varying Li-content, $x=0.1,0.2$, and 0.5 . These samples are $\mathrm{Na}_{2.1} \mathrm{Zn}_{1.9} \mathrm{Li}_{0.1} \mathrm{TeO}_{6}, \quad \mathrm{Na}_{2.2} \mathrm{Zn}_{1.8} \mathrm{Li}_{0.2} \mathrm{TeO}_{6}$, and $\mathrm{Na}_{2.5} \mathrm{Zn}_{1.5} \mathrm{Li}_{0.5} \mathrm{TeO}_{6}$, respectively. The ICP elemental analysis confirms that the compositions of Li-substituted NZTO are close to theoretical values as shown in Table S11. A thorough structural analysis of these compounds is presented in this section.

Figure 5 shows the SPXRD patterns of $\mathrm{Na}_{2.1} \mathrm{Zn}_{1.9} \mathrm{Li}_{0.1} \mathrm{TeO}_{6}$, $\mathrm{Na}_{2.2} \mathrm{Zn}_{1.8} \mathrm{Li}_{0.2} \mathrm{TeO}_{6}, \mathrm{Na}_{2.5} \mathrm{Zn}_{1.5} \mathrm{Li}_{0.5} \mathrm{TeO}_{6}$ as well as NZTO900

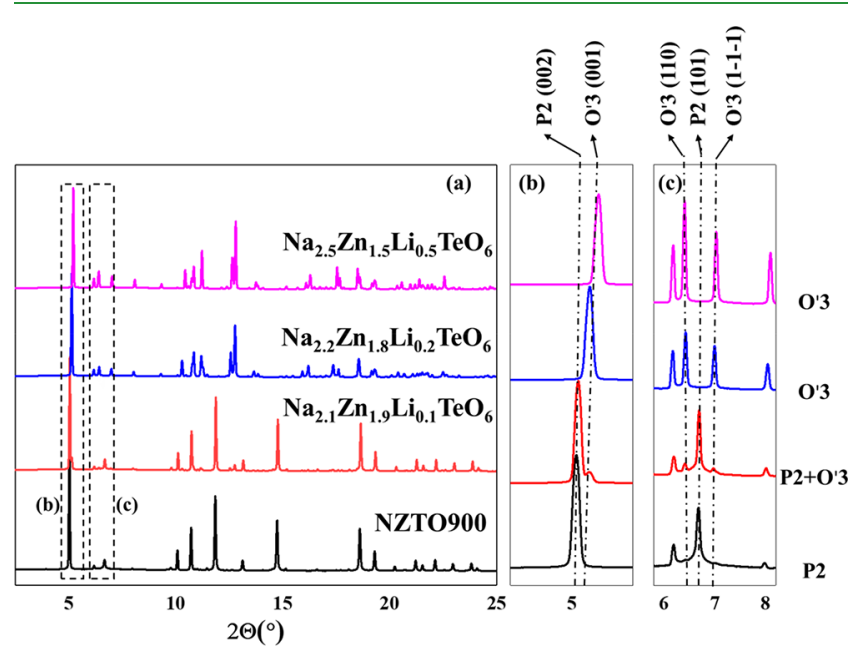

Figure 5. (a) SPXRD patterns of $\mathrm{Na}_{2+x} \mathrm{Li}_{x} \mathrm{Zn}_{2-x} \mathrm{TeO}_{6}(x=0.1,0.2$ and $0.5), \lambda=0.49426 \AA$. SPXRD pattern of NZTO900 is plotted for comparison (in black); (b) enlargement of $2 \theta$ range of 4.5 to $5.5^{\circ}$; and (c) enlargement of $2 \theta$ range of $5.8^{\circ}$ to $8.2^{\circ}$.

for comparison. The SPXRD pattern of $\mathrm{Na}_{2.1} \mathrm{Zn}_{1.9} \mathrm{Li}_{0.1} \mathrm{TeO}_{6}$ shows that even small amounts of Li-substitution induce the formation of the $\mathrm{O}^{\prime} 3$-type phase (cf. Figure 5). For larger Licontents $(0.2 \leq x \leq 0.5)$, the P2-type phase was no longer observed and a single $\mathrm{O}^{\prime} 3$-type phase is formed. Our attempts to further increase the Li-substitution for $\mathrm{Zn}$ up to $x=1.0$ led to melting of precursors and products during the calcination process, even at low temperature $\left(500^{\circ} \mathrm{C}\right)$.

The $\mathrm{X}$-ray scattering factor of $\mathrm{Li}$ is very low, making it difficult to determine Li positions from the SPXRD data. However, we can deduce the most likely $\mathrm{Li}$ positions from refined $\mathrm{Na}$ or $\mathrm{Zn}$ site occupancies. To do this we carried out four individual Rietveld refinements of $\mathrm{O}^{\prime} 3$ _model_2 with different constraints on the Te, $\mathrm{Zn}$, and Na site occupancies against SPXRD data of
$\mathrm{Na}_{2.5} \mathrm{Zn}_{1.5} \mathrm{Li}_{0.5} \mathrm{TeO}_{6}$ (the sample with the highest Li-content). Detailed information and corresponding refinement results can be found in the SI. In the second and third tests, the freely refined total $\mathrm{Zn}$ and $\mathrm{Na}$ occupancies are very close to the stoichiometric values for $\mathrm{Na}_{2.5} \mathrm{Zn}_{1.5} \mathrm{Li}_{0.5} \mathrm{TeO}_{6}$. Thus, in the final refinement, we constrained the total $\mathrm{Na}$ and $\mathrm{Zn}$ occupancies according to their stoichiometric values. All the diffraction peaks are well fitted and the refinement shows a lower $R_{\text {wp }}$ value compared to the other three models tested (see tests $1-3$ in Figure S10 and test 4 in Figure S11). On the basis of this we conclude that $\mathrm{Li}^{+}$ions occupy the $\mathrm{Zn}(4 g)$ site. Similar results are found when fitting the $\mathrm{O}^{\prime} 3$-type phase in $\mathrm{Na}_{2.2} \mathrm{Zn}_{1.8} \mathrm{Li}_{0.2} \mathrm{TeO}_{6}$ (see Figure 6). Similar studies were used to identify the $\mathrm{Li}$ positions in the coexisting $\mathrm{P} 2$ and $\mathrm{O}^{\prime} 3$-type phases of $\mathrm{Na}_{2.1} \mathrm{Zn}_{1.9} \mathrm{Li}_{0.1} \mathrm{TeO}_{6}$. The freely refined total $\mathrm{Na}$ (across $6 g, 2 a$, and $4 f$ sites) and $\mathrm{Zn}$ (across $2 b$ and $2 d$ sites) occupancies in P2type phase are close to their stoichiometric values for NZTO. However, the freely refined total $\mathrm{Na}$ (across $2 d$ and $4 h$ sites) and total $\mathrm{Zn}$ occupancies ( $4 g$ and $2 a$ sites) in the $\mathrm{O}^{\prime} 3$-type phase are 2.4 and 1.95 per formula unit. This indicates that the Na-content is sensitive to type of phase, and that a slight increase in $\mathrm{Na}$ content will convert the P2 to O'3-type phase. Detailed crystallographic parameters for $\mathrm{Na}_{2.5} \mathrm{Zn}_{1.5} \mathrm{Li}_{0.5} \mathrm{TeO}_{6}$, $\mathrm{Na}_{2.1} \mathrm{Zn}_{1.9} \mathrm{Li}_{0.1} \mathrm{TeO}_{6}$, and $\mathrm{Na}_{2.2} \mathrm{Zn}_{1.8} \mathrm{Li}_{0.2} \mathrm{TeO}_{6}$ are summarized in the SI (Tables S12-S14). With increasing Na-content, the $c$ axis in $\mathrm{P} 2$-type $\mathrm{Na}_{2.1} \mathrm{Zn}_{1.9} \mathrm{Li}_{0.1} \mathrm{TeO}_{6}$ shrinks compared to that of NZTO900. This is probably due to lower electrostatic repulsion between interlayer oxygen anions with increased $\mathrm{Na}$-content. $^{22,66}$ A similar trend was observed for the $c$-axis of the O'3-type phase which decreases with increasing Na-content (cf. Table 3).

Finally, we used DFT calculations to confirm the most likely $\mathrm{Li}$ locations in the $\mathrm{O}^{\prime} 3$-type structure and verify the Rietveld results. We studied two different supercell configurations containing a single $\mathrm{Li}$ impurity atom: one with a $\mathrm{Li}^{+}$ion substituting $\mathrm{Na}^{+}$and a second one with $\mathrm{Li}^{+}$at the $\mathrm{Zn}^{2+}$ site and an additional $\mathrm{Na}^{+}$ion placed at one of the $d$ sites. Note that three distinct $d$-type sites can be occupied within a layer of our supercell model; these sites are no longer equivalent due to the presence of the $\mathrm{Li}^{+}$ion, and a separate calculation needs to be performed for each structure to find the most favorable configuration. Sodium is found to occupy the site nearest to the Li dopant at a separation distance of $3.23 \AA$. The other sites, at 4.48 and $5.49 \AA$ from $\mathrm{Li}$, are found to be less favorable, but by only $50 \mathrm{meV}$. The formation energies of the two models, with stoichiometry $\mathrm{Na}_{2-x} \mathrm{Zn}_{2} \mathrm{Li}_{x} \mathrm{TeO}_{6}$ and $\mathrm{Na}_{2+x} \mathrm{Zn}_{2-x} \mathrm{Li}_{x} \mathrm{TeO}_{6}(x=$ 0.125 ) respectively, are calculated as follows:

$$
E_{\mathrm{Li} \rightarrow \mathrm{Na}}(n)=E\left(\mathrm{Na}_{N-n} \mathrm{Li}_{n}\right)-E\left(\mathrm{Na}_{N} \mathrm{Li}_{0}\right)+n\left(\mu_{\mathrm{Na}}-\mu_{\mathrm{Li}}\right)
$$



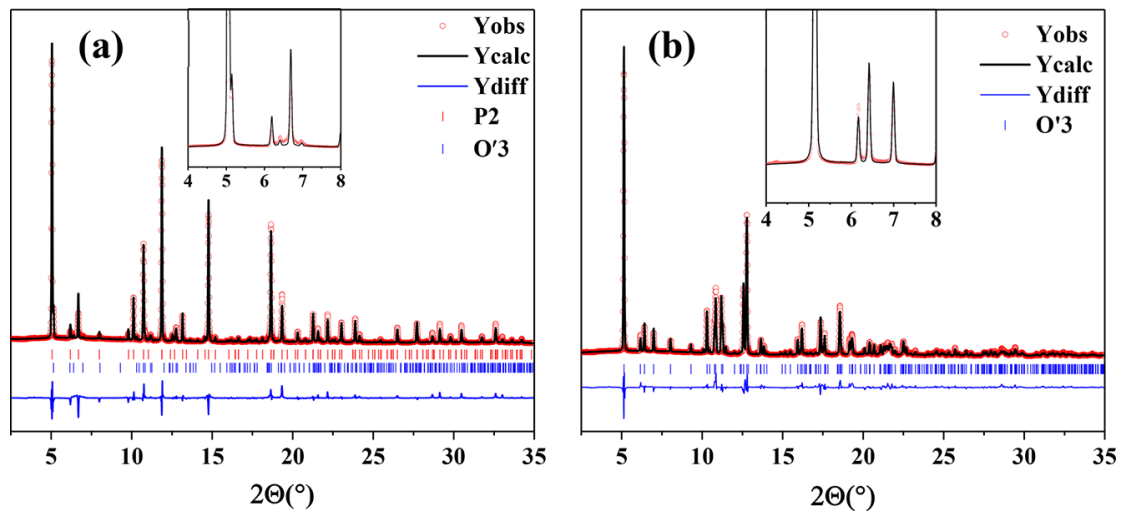

Figure 6. (a) Rietveld refinement against SPXRD data of $\mathrm{Na}_{2.1} \mathrm{Zn}_{1.9} \mathrm{Li}_{0.1} \mathrm{TeO}_{6}$ (Inset: enlargement of $2 \theta$ range of $4^{\circ}$ to $8^{\circ}$ ), Bragg positions of $\mathrm{P} 2$ and $\mathrm{O}^{\prime} 3$-type phases are in red and blue, respectively; (b) Rietveld refinement against SPXRD data of $\mathrm{Na}_{2.2} \mathrm{Zn}_{1.8} \mathrm{Li}_{0.2} \mathrm{TeO}_{6}$ (Inset: enlargement of $2 \theta$ range of $4^{\circ}$ to $\left.8^{\circ}\right)$, Bragg positions of $\mathrm{O}^{\prime} 3$-type phase are in blue. The experimental pattern is shown in red, calculated pattern in black, the difference between experimental and calculated curves in blue. Wavelength $(\lambda)$ for both SPXRD patterns is $0.49426 \AA$.

Table 3. Unit Cell Dimensions of P2 and $\mathrm{O}^{\prime} 3$-Type Phases Obtained from Rietveld Refinements against SPXRD Data of NZTO900, $\mathrm{Na}_{2.1} \mathrm{Zn}_{1.9} \mathrm{Li}_{0.1} \mathrm{TeO}_{6}, \mathrm{Na}_{2.2} \mathrm{Zn}_{1.8} \mathrm{Li}_{0.2} \mathrm{TeO}_{6}$, and $\mathrm{Na}_{2.5} \mathrm{Zn}_{1.5} \mathrm{Li}_{0.5} \mathrm{TeO}_{6}$

\begin{tabular}{|c|c|c|c|c|c|}
\hline \multirow[b]{2}{*}{ phase } & \multirow{2}{*}{$\frac{\text { NZTO900 }}{\text { P2 }}$} & \multicolumn{2}{|c|}{$\mathrm{Na}_{2.1} \mathrm{Zn}_{1.9} \mathrm{Li}_{0.1} \mathrm{TeO}_{6}$} & \multirow{2}{*}{$\frac{\mathrm{Na}_{2.2} \mathrm{Zn}_{1.8} \mathrm{Li}_{0.2} \mathrm{TeO}_{6}}{\mathrm{O}^{\prime} 3}$} & \multirow{2}{*}{$\frac{\mathrm{Na}_{2.5} \mathrm{Zn}_{1.5} \mathrm{Li}_{0.5} \mathrm{TeO}_{6}}{\mathrm{O}^{\prime} 3}$} \\
\hline & & P2 ( 91\%) & $\mathrm{O}^{\prime} 3(\sim 9 \%)$ & & \\
\hline space group & $P 6_{3} 22$ & $\mathrm{P}_{3} 22$ & $\mathrm{C} 2 / \mathrm{m}$ & $\mathrm{C} 2 / \mathrm{m}$ & $C 2 / m$ \\
\hline$a(\AA)$ & $5.2880(1)$ & $5.2803(1)$ & $5.3346(7)$ & $5.3181(1)$ & $5.3352(1)$ \\
\hline$b(\AA)$ & $5.2880(1)$ & $5.2803(1)$ & $9.198(1)$ & $9.1842(2)$ & $9.1714(1)$ \\
\hline$c(\AA)$ & $11.2388(2)$ & $11.2128(2)$ & $5.8209(5)$ & $5.8215(2)$ & $5.7370(1)$ \\
\hline$\beta(\operatorname{deg})$ & 90 & 90 & $109.05(1)$ & $108.920(2)$ & $108.774(1)$ \\
\hline $\mathrm{V}\left(\AA^{3}\right)$ & $272.17(1)$ & $270.75(1)$ & $270.00(6)$ & $268.97(1)$ & $265.78(1)$ \\
\hline$R_{\mathrm{wp}}(\%)$ & 6.38 & 9.84 & & 9.98 & 8.34 \\
\hline
\end{tabular}

$$
\begin{aligned}
E_{\mathrm{Li} \rightarrow \mathrm{Zn}}(n)= & E\left(\mathrm{Zn}_{N-n} \mathrm{Na}_{N+n} \mathrm{Li}_{n}\right)-E\left(\mathrm{Zn}_{N} \mathrm{Na}_{N} \mathrm{Li}_{0}\right) \\
& +n\left(\mu_{\mathrm{Zn}}-\mu_{\mathrm{Na}}-\mu_{\mathrm{Li}}\right)
\end{aligned}
$$

where $N$ is the number of $\mathrm{Na}^{+}$in the NZTO superstructure, $n$ the number of Li atoms inserted (in this case, $n=1$ ), and $E$ is the total energy evaluated at the indicated stoichiometry with lithium in the aforementioned sites. The chemical potential $\mu_{Z}$ $(Z=\mathrm{Li}, \mathrm{Na}, \mathrm{Zn})$, used to balance the stoichiometry between the doped and reference structures, is calculated for the equilibrium crystal structure (bcc for $\mathrm{Li}, \mathrm{Na}$; hcp for $\mathrm{Zn}$ ). With these conventions, negative formation energies indicate that the indicated defect is favorable. The values thus calculated are $E_{\mathrm{Li} \rightarrow \mathrm{Na}}=-0.05 \mathrm{eV}$ and $E_{\mathrm{Li} \rightarrow \mathrm{Zn}}=-4.61 \mathrm{eV}$, indicating a clear preference for a configuration of the second type. This is due to the availability of vacant $\mathrm{Na}$ sites in the crystal, which allow incorporation of additional $\mathrm{Na}$ without introducing major deformations. We note that this is not the case for the P2-type structure. In this phase, additional Na would locally suppress the reconstruction of the $\mathrm{Na}$ sublattice and favor occupancy of $g$ type sites, as demonstrated in our previous investigation. ${ }^{35,65} \mathrm{~A}$ nonreconstructed P2-type structure is least favorable, as shown in Figure 4(a), to the extent that the $\mathrm{O}^{\prime} 3$-type phase becomes dominant.

3.2. $\mathrm{Na}^{+}$Ion Conductivity. The $\mathrm{Na}^{+}$ion conductivity of NZTO500-900 and Li-substituted NZTO samples was measured using AC impedance spectroscopy. Nyquist plots for NZTO500-900 pellets measured at $148{ }^{\circ} \mathrm{C}$ and Li-doped NZTO pellets measured at $122{ }^{\circ} \mathrm{C}$ are presented in Figures $\mathrm{S} 12(\mathrm{a}-\mathrm{e})$ and $\mathrm{S} 13(\mathrm{a}-\mathrm{c})$, respectively. In the Nyquist plots of NZTO500-700, $\mathrm{Na}_{2.2} \mathrm{Zn}_{1.8} \mathrm{Li}_{0.2} \mathrm{TeO}_{6}$, and $\mathrm{Na}_{2.5} \mathrm{Zn}_{1.5} \mathrm{Li}_{0.5} \mathrm{TeO}_{6}$, a semicircle in high frequency region and a sloping line in low frequency region were observed, corresponding to bulk contribution of a material and ionic blocking effect, respectively. ${ }^{67}$ The sloping line in the low frequency region indicates that the conductivity in all the samples is ionic in nature. $^{3,68}$ At higher synthesis temperature or lower $\mathrm{Li}$ substitution $(x)$, the measured radius of the semicircle decreases. The shape of these semicircles is slightly different, which indicates different physical meanings. In the case of NZTO500 and NZTO600, the semicircles are very symmetric, are described using an equivalent circuit consisting of a resistance $(R)$ and a constant phase element (CPE). The capacitances obtained from the fits are in the order of $\mathrm{pF}$, indicating the conductivity contribution mainly originates from the bulk. ${ }^{69}$ While for NZTO 700, $\mathrm{Na}_{2.2} \mathrm{Zn}_{1.8} \mathrm{Li}_{0.2} \mathrm{TeO}_{6}$, and $\mathrm{Na}_{2.5} \mathrm{Zn}_{1.5} \mathrm{Li}_{0.5} \mathrm{TeO}_{6}$, the semicircles of the Nyquist plots are asymmetric, merged by two individual semicircles. We adapted two [RCPE] circuits to describe these asymmetric semicircles. The obtained capacitances from the fits are in the range of $\mathrm{pF}$ and $\mathrm{nF}$, corresponding to the bulk and grain boundary contribution, respectively. In the Nyquist plots of NZTO800, NZTO900, and $\mathrm{Na}_{2.1} \mathrm{Zn}_{1.9} \mathrm{Li}_{0.1} \mathrm{TeO}_{6}$, the semicircle disappears and only a sloping line is observed, indicating excellent conductivity. A simple resistance representing the total resistance was adapted to describe the linear behavior in the high frequency range. Because it is impossible to distinguish the bulk and grain boundary contribution from the Nyquist plots of NZTO500, NZTO600, NZTO800, NZTO900, and $\mathrm{Na}_{2.1} \mathrm{Zn}_{1.9} \mathrm{Li}_{0.1} \mathrm{TeO}_{6}$, total conductivity (the sum of the bulk and grain boundary contribution) is calculated here. The $\mathrm{Na}^{+}$ ion conductivity for NZTO500-900 and Li-doped NZTO samples was calculated based on eq 3 , 


$$
\sigma(T)=\frac{d}{R(T) S}
$$

where $\sigma(\mathrm{S} / \mathrm{cm})$ refers to $\mathrm{Na}^{+}$ion conductivity, $d(\mathrm{~cm})$ is the thickness of pellet, $S\left(\mathrm{~cm}^{2}\right)$ is the area of the silver paste, and $R$ $(\Omega)$ is the sum of bulk and grain boundary resistance.

Figure $7(\mathrm{a}, \mathrm{b})$ presents the temperature dependence of the conductivities for NZTO500-900 and Li-substituted NZTO
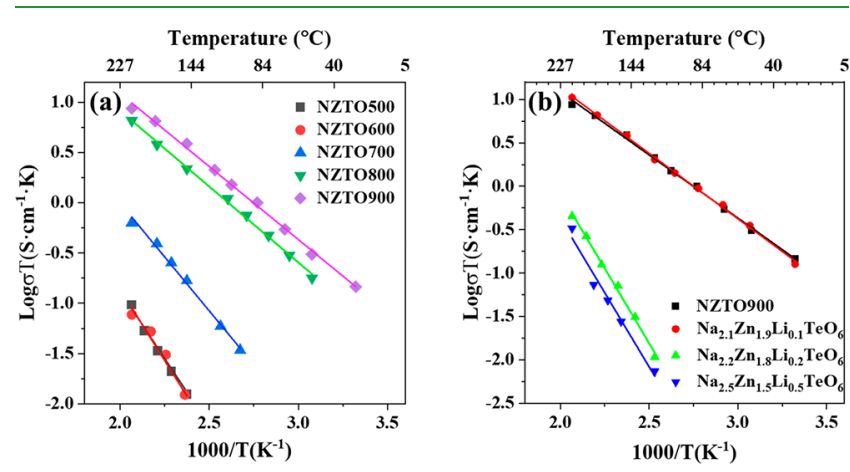

Figure 7. (a) Arrhenius plots for NZTO 500-900 samples within temperature range from room temperature to $211^{\circ} \mathrm{C}$; (b) Arrhenius plots for NZTO900 (for comparison), $\mathrm{Na}_{2.1} \mathrm{Zn}_{1.9} \mathrm{Li}_{0.1} \mathrm{TeO}_{6}$, $\mathrm{Na}_{2.2} \mathrm{Zn}_{1.8} \mathrm{Li}_{0.2} \mathrm{TeO}_{6}$, and $\mathrm{Na}_{2.5} \mathrm{Zn}_{1.5} \mathrm{Li}_{0.5} \mathrm{TeO}_{6}$ within the temperature range from room temperature to $211^{\circ} \mathrm{C}$.

samples. Data points for each sample obey the Arrhenius law, and the corresponding fitting results are shown in Figure 7. Activation energies $\left(E_{\mathrm{a}}, \mathrm{eV}\right)$ for $\mathrm{Na}^{+}$ion diffusion were calculated from the slopes of the linear fits using the Arrhenius eq 4 (see Table S15),

$$
\sigma(T)=\frac{A}{T} \times \exp \left(-\frac{E_{\mathrm{a}}}{k T}\right)
$$

where $T$ is the absolute temperature in $\mathrm{K}$; $A$ is a constant, and $k$ is the Boltzmann constant. So-calculated activation energies $E_{a}$ are listed in Table S15. The calculated activation energy for NZTO900 is $0.289(6) \mathrm{eV}$, which is comparable to the reported values in previous works as presented in Table S16. ${ }^{23,24}$ The activation energy increases with increasing fraction of the $\mathrm{O}^{\prime} 3$ type phase, Figure 8 . This large difference in activation energy (a)

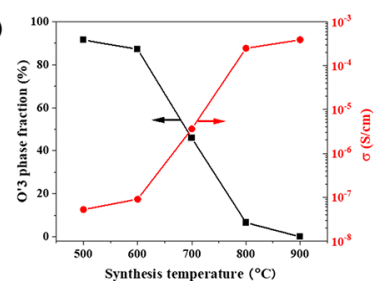

(b)

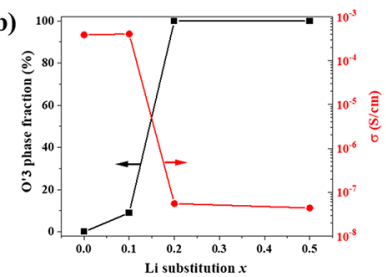

Figure 8. $\mathrm{O}^{\prime} 3$-type phase fraction (in black line with square symbol) and $\mathrm{Na}^{+}$ion conductivities (in red line with circle symbol) as a function of (a) synthesis temperature and (b) Li-content $(0 \leq x \leq 0.5)$.

between $\mathrm{P} 2$ and $\mathrm{O}^{\prime}$ 3-type phases indicates that $\mathrm{Na}^{+}$ions diffuse much faster in the P2-type phase. This is consistent with earlier studies on layered Na-based oxides. ${ }^{14,17,20,70}$

Due to the high fraction of the O'3-type phase in NZTO500700, $\mathrm{Na}_{2.2} \mathrm{Zn}_{1.8} \mathrm{Li}_{0.2} \mathrm{TeO}_{6}$ and $\mathrm{Na}_{2.5} \mathrm{Zn}_{1.5} \mathrm{Li}_{0.5} \mathrm{TeO}_{6}$, reliable impedance data could not be obtained at room temperature. We therefore calculated the conductivities at $25{ }^{\circ} \mathrm{C}$ for these samples by extrapolating the Arrhenius plots. The obtained $\mathrm{Na}^{+}$ ion conductivities are summarized in Table S15. The derived $\mathrm{Na}^{+}$ion conductivities of NZTO500-900 and Li-doped NZTO samples at room temperature decrease with increasing sample synthesis temperature, and thereby the fraction of the O'3-type phase as shown in Figure 8. The $\mathrm{Na}^{+}$ion conductivity of NZTO500 (@25 ${ }^{\circ} \mathrm{C}$ ) is 4 orders of magnitude lower than NZTO900. An analogous result is observed for the Lisubstituted NZTO samples. The $\mathrm{Na}^{+}$ion conductivities of $\mathrm{Na}_{2.1} \mathrm{Zn}_{1.9} \mathrm{Li}_{0.1} \mathrm{TeO}_{6}$ and NZTO800 are on the same order of magnitude $\left(\sim 10^{-4} \mathrm{~S} / \mathrm{cm} @ 25{ }^{\circ} \mathrm{C}\right)$ as that for NZTO900, comparable to reported room temperature conductivity for NZTO as shown in Table S16. This might be due to the low fraction of $\mathrm{O}^{\prime} 3$-type phase. With larger Li substitution $(x)$, the $\mathrm{Na}^{+}$ion conductivity decreases to $\sim 10^{-8} \mathrm{~S} / \mathrm{cm}\left(@ 25{ }^{\circ} \mathrm{C}\right.$ ) for $\mathrm{Na}_{2.2} \mathrm{Zn}_{1.8} \mathrm{Li}_{0.2} \mathrm{TeO}_{6}$ and $\mathrm{Na}_{2.5} \mathrm{Zn}_{1.5} \mathrm{Li}_{0.5} \mathrm{TeO}_{6}$.

We rationalized the diffusion mechanism within these structures with DFT calculations. We implement our NEB calculations by initially introducing a vacancy into the systems. The presence of such defects hinders the formation of the nonhexagonal reconstruction of the $\mathrm{Na}$ sublattice, ${ }^{65}$ resulting in a disordered structure with a much larger occupancy of $g$-type sites. Such an arrangement is not suitable for an NEB calculation due to the ambiguous definition of a percolating path between a $\mathrm{Na}^{+}$site and an equivalent one. We therefore approximate the P2 system with the nonreconstructed model. The reaction coordinates and the associated energetics are shown in Figure 9 in panels (b) and (a), respectively. It is evident that the

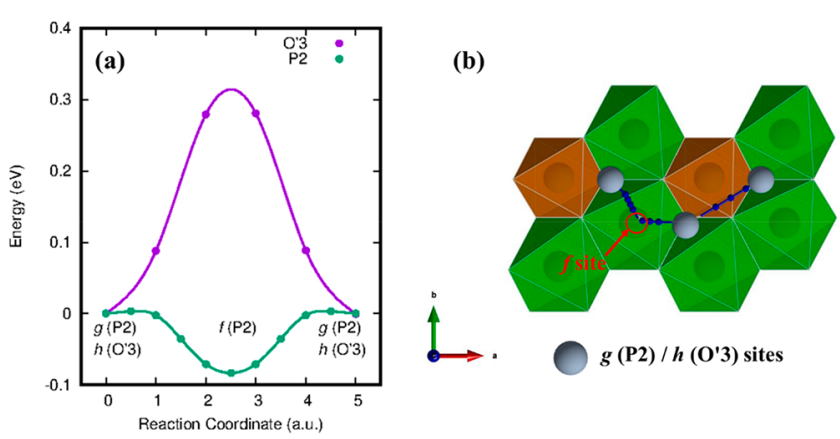

Figure 9. Energetics along the reaction coordinate for a diffusing $\mathrm{Na}^{+}$ ion. (a) Schematized reaction coordinate for diffusing $\mathrm{Na}^{+}$ions in the $\mathrm{P} 2$ and $\mathrm{O}^{\prime} 3$-type phases. Small, blue spheres indicate the ion position in the replicas of the system along the reaction coordinate (b).

diffusion mechanism is very different in the two phases. In the $\mathrm{O}^{\prime} 3$ case, the diffusion path is linear, and the saddle point is located in the intermediate position between the initial and final $\mathrm{Na}$ sites. The activation energy is estimated to be $0.32 \mathrm{eV}$. In the P2-type phase, the $\mathrm{Na}^{+}$ions diffuse first to the $f$-type site, where a more favorable configuration is encountered, a local version of the aforementioned sublattice reconstruction. As a consequence, the saddle points are located at the initial and final configurations (i.e., the g-type sites) and the associated activation energy is $0.09 \mathrm{eV}$. These results highly agree with previous investigation on the $\mathrm{Na}$ mobility difference between the $\mathrm{P} 2$ and $\mathrm{O}^{\prime} 3$-type phase. ${ }^{71}$

The calculated activation energies are in both cases much lower than the experimental values. This is probably the combined effect of (i) a vacancy being introduced into the system and (ii) the diffusion process being modeled as isolated hops. The former effect is well-known in literature, as even a small concentration of vacant sites can be shown to greatly 
increase the ionic mobility. ${ }^{72}$ The presence of an isolated $\mathrm{Na}$ vacancy is, however, required to construct the minimum energy diffusive path within the NEB method. Moreover, we believe that the mobility in the P2 case is not due to isolated hops, but it rather depends on the continuous rearrangement of interacting $\mathrm{Na}^{+}$ions. The only way of correctly capturing this phenomenon is through $\mathrm{ab}$ initio molecular dynamics simulations. This investigation would require a significant effort in terms of computational resources and will be pursued in a future manuscript. Despite the underestimated activation energies, the NEB correctly reproduces the physical trends of the diffusive process: the energy barrier is much lower in the P2-type phase due to the presence of a stable intermediate site which is not found in the $\mathrm{O}^{\prime} 3$ case.

\section{CONCLUSIONS}

We have investigated the influence of synthesis temperature and Li-doping on the structural properties and $\mathrm{Na}^{+}$ion conductivity for NZTO using SPXRD, DFT, and EIS. The main conclusions are as follows:

1. The pure P2-type NZTO can only be obtained at synthesis temperature of $900{ }^{\circ} \mathrm{C}$. Lower synthesis temperature produces a significant amount of the $\mathrm{O}^{\prime} 3$ type phase. To the best of our knowledge, this is the first report of such a phase, which crystallizes according the $\mathrm{C} 2 / \mathrm{m}$ space group. The fraction of $\mathrm{O}^{\prime} 3$-type phase decreases with increasing synthesis temperature. This is consistent with in situ PXRD studies of the synthesis process.

2. Solid solution of $\mathrm{Li}$-doped $\mathrm{Na}_{2+x} \mathrm{Zn}_{2-x} \mathrm{Li}_{x} \mathrm{TeO}_{6}(x=0.1$, 0.2 and 0.5$)$ were prepared. Low Li-doping $(x=0.1)$ induces a partial $\mathrm{O}^{\prime} 3$-type phase with $\mathrm{P} 2$ as the dominant phase. A single phase $\mathrm{O}^{\prime} 3$-type NZTO was obtained, for the first time, at higher Li-doping levels $(x=0.2$ and 0.5$)$. Rietveld refinements prove that $\mathrm{Li}$ enters corresponding $\mathrm{Zn}$ site $(4 g)$ in $\mathrm{O}^{\prime} 3$-type phases. This result is backed by DFT-calculated defect formation energies.

3. The P2-type phase has better $\mathrm{Na}^{+}$mobility, due the presence of stable interstitial sites. This is in good agreement with theoretical predictions that the activation energy for $\mathrm{Na}^{+}$ion diffusion in $\mathrm{P} 2$ is much lower than that in the $\mathrm{O}^{\prime} 3$-type phase.

By clarifying the synthesis and structure of the NZTO materials, we hope to bring their practical application in SIB systems one step closer.

\section{ASSOCIATED CONTENT}

\section{SI Supporting Information}

The Supporting Information is available free of charge at https://pubs.acs.org/doi/10.1021/acsami.0c05863.

Additional refinements against SPXRD data, tables for crystallographic information, schematic illustration of the monoclinic and hexagonal lattice for NZTO, tables for sodium occupancy and fitting parameters to the equation of state, elastic constants tensor for P2 and $\mathrm{O}^{\prime} 3$-type phases from computational modeling and fitting of Nyquist plots, and a table for $\mathrm{Na}^{+}$ion conductivities of reported $\mathrm{Na}_{2} \mathrm{M}_{2} \mathrm{TeO}_{6}(\mathrm{PDF})$

\section{AUTHOR INFORMATION}

\section{Corresponding Authors}

Xinyu Li - Department of Chemistry and Center for Materials Science and Nanotechnology, University of Oslo, Oslo 0371, Norway; 이이이.org/0000-0002-7853-6724; Email: xinyu.li@smn.uio.no

Helmer Fjellvåg - Department of Chemistry and Center for Materials Science and Nanotechnology, University of Oslo, Oslo 0371, Norway; Email: helmer.fjellvag@kjemi.uio.no

\section{Authors}

Federico Bianchini - Department of Chemistry and Center for Materials Science and Nanotechnology, University of Oslo, Oslo 0371, Norway; ○ orcid.org/0000-0002-9016-4820

Julia Wind - Department of Chemistry and Center for Materials Science and Nanotechnology, University of Oslo, Oslo 0371, Norway; (i) orcid.org/0000-0001-6325-4727

Christine Pettersen - Department of Chemistry and Center for Materials Science and Nanotechnology, University of Oslo, Oslo 0371, Norway

David S. Wragg - Department of Chemistry and Center for Materials Science and Nanotechnology, University of Oslo, Oslo 0371, Norway

Ponniah Vajeeston - Department of Chemistry and Center for Materials Science and Nanotechnology, University of Oslo, Oslo 0371, Norway

Complete contact information is available at:

https://pubs.acs.org/10.1021/acsami.0c05863

\section{Notes}

The authors declare no competing financial interest.

\section{ACKNOWLEDGMENTS}

We thank the Research Council of Norway (Grant agreement SELiNaB-255441) for financial support. We acknowledge use of the Norwegian national resource center for X-ray diffraction and scattering (NFR project number 208896) and the SwissNorwegian Beamlines (SNBL) at the ESRF. Computer time on the Norwegian supercomputer UNINETTSigma2 AS facility (project numbers NN2875k, NS2875K) is gratefully acknowledged.

\section{REFERENCES}

(1) Palomares, V.; Casas-Cabanas, M.; Castillo-Martínez, E.; Han, M. H.; Rojo, T. Update on Na-Based Battery Materials. A Growing Research Path. Energy Environ. Sci. 2013, 6, 2312-2337.

(2) Yabuuchi, N.; Kubota, K.; Dahbi, M.; Komaba, S. Research Development on Sodium-Ion Batteries. Chem. Rev. 2014, 114, 1163611682.

(3) Wagner, R.; Redhammer, G. J.; Rettenwander, D.; Tippelt, G.; Welzl, A.; Taibl, S.; Fleig, J.; Franz, A.; Lottermoser, W.; Amthauer, G. Fast Li-Ion-Conducting Garnet-Related $\mathrm{Li}_{7-3 x} \mathrm{Fe}_{x} \mathrm{La}_{3} \mathrm{Zr}_{2} \mathrm{O}_{12}$ with Uncommon I433d Structure. Chem. Mater. 2016, 28, 5943-5951.

(4) Zhao, C.; Liu, L.; Qi, X.; Lu, Y.; Wu, F.; Zhao, J.; Yu, Y.; Hu, Y.; Chen, L. Solid-State Sodium Batteries. Adv. Energy Mater. 2018, 8, 1703012.

(5) Goodenough, J. B. Rechargeable batteries: challenges old and new. J. Solid State Electrochem. 2012, 16, 2019-2029.

(6) Richards, W. D.; Miara, L. J.; Wang, Y.; Kim, J. C.; Ceder, G. Interface Stability in Solid-State Batteries. Chem. Mater. 2016, 28, 266273.

(7) Goodenough, J. B.; Hong, H. Y.-P.; Kafalas, J. A. Fast $\mathrm{Na}^{+}$-ion Transport in Skeleton Structures. Mater. Res. Bull. 1976, 11, 203-220. 
(8) Ma, Q.; Guin, M.; Naqash, S.; Tsai, C. L.; Tietz, F.; Guillon, O. Scandium-Substituted $\mathrm{Na}_{3} \mathrm{Zr}_{2}\left(\mathrm{SiO}_{4}\right)_{2}\left(\mathrm{PO}_{4}\right)$ Prepared by a SolutionAssisted Solid-State Reaction Method as Sodium-Ion Conductors. Chem. Mater. 2016, 28, 4821-4828.

(9) Park, H.; Jung, K.; Nezafati, M.; Kim, C. S.; Kang, B. Sodium Ion Diffusion in Nasicon $\left(\mathrm{Na}_{3} \mathrm{Zr}_{2} \mathrm{Si}_{2} \mathrm{PO}_{12}\right)$ Solid Electrolytes: Effects of Excess Sodium. ACS Appl. Mater. Interfaces 2016, 8, 27814-27824.

(10) Kummer, J. T. $\beta$-Alumina Electrolytes. Prog. Solid State Chem. 1972, 7, 141-175.

(11) Muthuraman, G.; Boyeol, L.; Il-Shik, M. Na- $\beta$-Alumina as a Separator in the Development of All-Vanadium Non-Aqueous Tubular Redox Flow Batteries: An Electrochemical and Charging-Discharging Examination Using a Prototype Tubular Redox Flow Cell. J. Electrochem. Soc. 2018, 165, A1920-A1924.

(12) Noi, K.; Hayashi, A.; Tatsumisago, M. Structure and Properties of the $\mathrm{Na}_{2} \mathrm{~S}-\mathrm{P}_{2} \mathrm{~S}_{5}$ Glasses and Glass-Ceramics Prepared by Mechanical Milling. J. Power Sources 2014, 269, 260-265.

(13) Fouassier, C.; Delmas, C.; Hagenmuller, P. Evolution Structurale Et Proprietes Physiques Des Phases $A_{X} M O_{2}(A=\mathrm{Na}, \mathrm{K} ; M=\mathrm{Cr}, \mathrm{Mn}$, Co) $(x \leqslant 1)$. Mater. Res. Bull. 1975, 10, 443-449.

(14) Delmas, C.; Fouassier, C.; Reau, J. M.; Hagenmuller, P. Sur De Nouveaux Conducteurs Ioniques A Structure Lamellaire. Mater. Res. Bull. 1976, 11, 1081-1086.

(15) Delmas, C.; Fouassier, C.; Hagenmuller, P. Structural Classification and Properties of the Layered Oxides. Physica B+C 1980, 99, 81-85.

(16) Gonzalo, E.; Han, M. H.; López del Amo, J. M.; Acebedo, B.; Casas-Cabanas, M.; Rojo, T. Synthesis and Characterization of Pure P2- and O3- $\mathrm{Na}_{2 / 3} \mathrm{Fe}_{2 / 3} \mathrm{Mn}_{1 / 3} \mathrm{O}_{2}$ as Cathode Materials for $\mathrm{Na}$ Ion Batteries. J. Mater. Chem. A 2014, 2, 18523-18530.

(17) Guo, S.; Liu, P.; Yu, H.; Zhu, Y.; Chen, M.; Ishida, M.; Zhou, H. Angew. Chem., Int. Ed. 2015, 54, 5894-5899.

(18) Sharma, N.; Gonzalo, E.; Pramudita, J. C.; Han, M. H.; Brand, H. E. A.; Hart, J. N.; Pang, W. K.; Guo, Z.; Rojo, T. The Unique Structural Evolution of the O3-Phase $\mathrm{Na}_{2 / 3} \mathrm{Fe}_{2 / 3} \mathrm{Mn}_{1 / 3} \mathrm{O}_{2}$ during High Rate Charge/Discharge: A Sodium-Centred Perspective. Adv. Funct. Mater. 2015, 25, 4994-5005.

(19) Katcho, N. A.; Carrasco, J.; Saurel, D.; Gonzalo, E.; Han, M.; Aguesse, F.; Rojo, T. Origins of Bistability and Na Ion Mobility Difference in P2- and O3- $\mathrm{Na}_{2 / 3} \mathrm{Fe}_{2 / 3} \mathrm{Mn}_{1 / 3} \mathrm{O}_{2}$ Cathode Polymorphs. Adv. Energy Mater. 2017, 7, 1601477.

(20) Lee, E.; Lu, J.; Ren, Y.; Luo, X.; Zhang, X.; Wen, J.; Miller, D.; DeWahl, A.; Hackney, S.; Key, B.; Kim, D.; Slater, M. D.; Johnson, C. S. Layered P2/O3 Intergrowth Cathode: Toward High Power Na-Ion Batteries. Adv. Energy Mater. 2014, 4, 1400458.

(21) Lei, Y.; Li, X.; Liu, L.; Ceder, G. Synthesis and Stoichiometry of Different Layered Sodium Cobalt Oxides. Chem. Mater. 2014, 26, $5288-5296$.

(22) Carlier, D.; Cheng, J. H.; Berthelot, R.; Guignard, M.; Yoncheva, M.; Stoyanova, R.; Hwang, B. J.; Delmas, C. The P2$\mathrm{Na}_{2 / 3} \mathrm{Co}_{2 / 3} \mathrm{Mn}_{1 / 3} \mathrm{O}_{2}$ Phase: Structure, Physical Properties and Electrochemical Behavior as Positive Electrode in Sodium Battery. Dalton Trans. 2011, 40, 9306-9312.

(23) Evstigneeva, M. A.; Nalbandyan, V. B.; Petrenko, A. A.; Medvedev, B. S.; Kataev, A. A. A New Family of Fast Sodium Ion Conductors: $\mathrm{Na}_{2} \mathrm{M}_{2} \mathrm{TeO}_{6}(M=\mathrm{Ni}, \mathrm{Co}, \mathrm{Zn}, \mathrm{Mg})$. Chem. Mater. 2011, 23, 1174-1181.

(24) Li, Y.; Deng, Z.; Peng, J.; Chen, E.; Yu, Y.; Li, X.; Luo, J.; Huang, Y.; Zhu, J.; Fang, C.; Li, Q.; Han, J.; Huang, Y. A P2-Type Layered Superionic Conductor Ga-Doped $\mathrm{Na}_{2} \mathrm{Zn}_{2} \mathrm{TeO}_{6}$ for All-Solid-State Sodium-Ion Batteries. Chem. - Eur. J. 2018, 24, 1057-1061.

(25) Xu, J.; Assoud, A.; Soheilnia, N.; Derakhshan, S.; Cuthbert, H. L.; Greedan, J. E.; Whangbo, M. H.; Kleinke, H. Synthesis, Structure, and Magnetic Properties of the Layered Copper(II) Oxide $\mathrm{Na}_{2} \mathrm{Cu}_{2} \mathrm{TeO}_{6}$. Inorg. Chem. 2005, 44, 5042-5046.

(26) Yao, H. R.; Lv, W. J.; Yin, Y. X.; Ye, H.; Wu, X.-W.; Wang, Y.; Gong, Y.; Li, Q.; Yu, X.; Gu, L.; Huang, Z.; Guo, Y. G. Suppression of Monoclinic Phase Transitions of O3-Type Cathodes Based on
Electronic Delocalization for Na-Ion Batteries. ACS Appl. Mater. Interfaces 2019, 11, 22067-22073.

(27) Stoyanova, R.; Carlier, D.; Sendova-Vassileva, M.; Yoncheva, M.; Zhecheva, E.; Nihtianova, D.; Delmas, C. Stabilization of OverStoichiometric $\mathrm{Mn}^{4+}$ in Layered $\mathrm{Na}_{2 / 3} \mathrm{MnO}_{2}$. J. Solid State Chem. 2010, $183,1372-1379$.

(28) Mortemard de Boisse, B.; Carlier, D.; Guignard, M.; Bourgeois, L.; Delmas, C. P2- $\mathrm{Na}_{x} \mathrm{Mn}_{1 / 2} \mathrm{Fe}_{1 / 2} \mathrm{O}_{2}$ Phase Used as Positive Electrode in Na Batteries: Structural Changes Induced by the Electrochemical (De)Intercalation Process. Inorg. Chem. 2014, 53, 11197-11205.

(29) Shacklette, L. W.; Jow, T. R.; Townsend, L. Rechargeable Electrodes from Sodium Cobalt Bronzes. J. Electrochem. Soc. 1988, 135, 2669-2674.

(30) Carlier, D.; Blangero, M.; Menetrier, M.; Pollet, M.; Doumerc, J. P.; Delmas, C. Sodium Ion Mobility in $\mathrm{Na}_{x} \mathrm{CoO}_{2}(0.6<x<0.75)$ Cobaltites Studied by ${ }^{23} \mathrm{Na}$ MAS NMR. Inorg. Chem. 2009, 48, 70187025.

(31) Berthelot, R.; Schmidt, W.; Sleight, A. W.; Subramanian, M. A. Studies on Solid Solutions Based on Layered Honeycomb-Ordered Phases P2- $\mathrm{Na}_{2} \mathrm{M}_{2} \mathrm{TeO}_{6}(M=C o, N i, \mathrm{Zn})$. J. Solid State Chem. 2012, 196, 225-231.

(32) Gupta, A.; Mullins, C. B.; Goodenough, J. B. $\mathrm{Na}_{2} \mathrm{Ni}_{2} \mathrm{TeO}_{6}$ : Evaluation as A Cathode for Sodium Battery. J. Power Sources 2013, 243, 817-821.

(33) Viciu, L.; Huang, Q.; Morosan, E.; Zandbergen, H. W.; Greenbaum, N. I.; McQueen, T.; Cava, R. J. Structure and Basic Magnetic Properties of the Honeycomb Lattice Compounds $\mathrm{Na}_{2} \mathrm{Co}_{2} \mathrm{TeO}_{6}$ and $\mathrm{Na}_{3} \mathrm{Co}_{2} \mathrm{SbO}_{6}$. J. Solid State Chem. 2007, 180, 1060-1067.

(34) Li, Y.; Deng, Z.; Peng, J.; Gu, J.; Chen, E.; Yu, Y.; Wu, J.; Li, X.; Luo, J.; Huang, Y.; Xu, Y.; Gao, Z.; Fang, C.; Zhu, J.; Li, Q.; Han, J.; Huang, Y. New P2-Type Honeycomb-Layered Sodium-Ion Conductor: $\mathrm{Na}_{2} \mathrm{Mg}_{2} \mathrm{TeO}_{6}$. ACS Appl. Mater. Interfaces 2018, 10, 1576015766.

(35) Li, X.; Bianchini, F.; Wind, J.; Vajeeston, P.; Wragg, D.; Fjellvåg, H. P2 Type Layered Solid-State Electrolyte $\mathrm{Na}_{2} \mathrm{Zn}_{2} \mathrm{TeO}_{6}$ : Crystal Structure and Stacking Faults. J. Electrochem. Soc. 2019, 166, A3830A3837.

(36) Wu, J.-F.; Yu, Z.-Y.; Wang, Q.; Guo, X. High Performance AllSolid-State Sodium Batteries Actualized by Polyethylene Oxide/ $\mathrm{Na}_{2} \mathrm{Zn}_{2} \mathrm{TeO}_{6}$ Composite Solid Electrolytes. Energy Storage Mater. 2020, 24, 467-471.

(37) Sau, K.; Kumar, P. P. Role of Ion-Ion Correlations on Fast Ion Transport: Molecular Dynamics Simulation of $\mathrm{Na}_{2} \mathrm{Ni}_{2} \mathrm{TeO}_{6}$. J. Phys. Chem. C 2015, 119, 18030-18037.

(38) Sau, K.; Kumar, P. P. Ion Transport in $\mathrm{Na}_{2} \mathrm{M}_{2} \mathrm{TeO}_{6}$ : Insights from Molecular Dynamics Simulation. J. Phys. Chem. C 2015, 119, $1651-1658$

(39) Sau, K. Influence of Ion-Ion Correlation on $\mathrm{Na}^{+}$Transport in $\mathrm{Na}_{2} \mathrm{Ni}_{2} \mathrm{TeO}_{6}$ : Molecular Dynamics Study. Ionics 2016, 22, 2379-2385.

(40) Deng, Z.; Gu, J.; Li, Y.; Li, S.; Peng, J.; Li, X.; Luo, J.; Huang, Y.; Fang, C.; Li, Q.; Han, J.; Huang, Y.; Zhao, Y. Ca-Doped $\mathrm{Na}_{2} \mathrm{Zn}_{2} \mathrm{TeO}_{6}$ Layered Sodium Conductor for All-Solid-State Sodium-Ion Batteries. Electrochim. Acta 2019, 298, 121-126.

(41) Dubey, M.; Kumar, A.; Murugavel, S.; Prakash, G. V.; Jose, D. A.; Mariappan, C. R. Structural and Ion Transport Properties of Sodium Ion Conducting $\mathrm{Na}_{2} \mathrm{MTeO}_{6}(\mathrm{M}=\mathrm{MgNi}$ and $\mathrm{MgZn})$ Solid Electrolytes. Ceram. Int. 2020, 46, 663-671.

(42) Fjellvag, O. S.; Armstrong, J.; Slawinski, W. A.; Sjastad, A. O. Thermal and Structural Aspects of the Hydride-Conducting Oxyhydride $\mathrm{La}_{2} \mathrm{LiHO}_{3}$ Obtained via a Halide Flux Method. Inorg. Chem. 2017, 56, 11123-11128.

(43) Sottmann, J.; Bernal, F. L. M.; Yusenko, K. V.; Herrmann, M.; Emerich, H.; Wragg, D. S.; Margadonna, S. In Operando Synchrotron $\mathrm{XRD} / \mathrm{XAS}$ Investigation of Sodium Insertion into the Prussian Blue Analogue Cathode Material $\mathrm{Na}_{1.32} \mathrm{Mn}\left[\mathrm{Fe}(\mathrm{CN})_{6}\right]_{0.83} \cdot z \mathrm{H}_{2} \mathrm{O}$. Electrochim. Acta 2016, 200, 305-313. 
(44) Coelho, A. A. TOPAS and TOPAS-Academic: An Optimization Program Integrating Computer Algebra and Crystallographic Objects Written in C++. J. Appl. Crystallogr. 2018, 51, 210-218.

(45) Momma, K.; Izumi, F. VESTA 3 for Three-Dimensional Visualization of Crystal, Volumetric and Morphology Data. J. Appl. Crystallogr. 2011, 44, 1272-1276.

(46) Kresse, G.; Hafner, J. Ab initio Molecular Dynamics for Liquid Metals. Phys. Rev. B: Condens. Matter Mater. Phys. 1993, 47, 558-561.

(47) Kresse, G.; Hafner, J. Ab initio Molecular-Dynamics Simulation of the Liquid-Metal-Amorphous-Semiconductor Transition in Germanium. Phys. Rev. B: Condens. Matter Mater. Phys. 1994, 49, 1425114269

(48) Kresse, G.; Furthmüller, J. Efficiency of ab-initio Total Energy Calculations for Metals and Semiconductors Using A Plane-Wave Basis Set. Comput. Mater. Sci. 1996, 6, 15-50.

(49) Kresse, G.; Furthmüller, J. Efficient Iterative Schemes for $a b$ initio Total-Energy Calculations Using A Plane-Wave Basis Set. Phys. Rev. B: Condens. Matter Mater. Phys. 1996, 54, 11169-11186.

(50) Perdew, J. P.; Burke, K.; Ernzerhof, M. Generalized Gradient Approximation Made Simple. Phys. Rev. Lett. 1996, 77, 3865-3868.

(51) Methfessel, M.; Paxton, A. T. High-Precision Sampling for Brillouin-Zone Integration in Metals. Phys. Rev. B: Condens. Matter Mater. Phys. 1989, 40, 3616-3621.

(52) Wu, X.; Vanderbilt, D.; Hamann, D. R. Systematic Treatment of Displacements, Strains and Electric Fields in Density-Functional Perturbation Theory. Phys. Rev. B: Condens. Matter Mater. Phys. 2005, 72, 035105

(53) Togo, A.; Oba, F.; Tanaka, I. First-Principles Calculations of the Ferroelastic Transition Between Rutile-Type and $\mathrm{CaCl}_{2}$-type $\mathrm{SiO}_{2}$ at High Pressures. Phys. Rev. B: Condens. Matter Mater. Phys. 2008, 78, 134106.

(54) Henkelman, G.; Jónsson, H. Improved Tangent Estimate in the Nudged Elastic Band Method for Finding Minimum Energy Paths and Saddle Points. J. Chem. Phys. 2000, 113, 9978-9985.

(55) Hjorth Larsen, A.; Jorgen Mortensen, J.; Blomqvist, J.; Castelli, I. E.; Christensen, R.; Dulak, M.; Friis, J.; Groves, M. N.; Hammer, B.; Hargus, C.; Hermes, E. D.; Jennings, P. C.; Bjerre Jensen, P.; Kermode, J.; Kitchin, J. R.; Leonhard Kolsbjerg, E.; Kubal, J.; Kaasbjerg, K.; Lysgaard, S.; Bergmann Maronsson, J.; Maxson, T.; Olsen, T.; Pastewka, L.; Peterson, A.; Rostgaard, C.; Schiotz, J.; Schutt, O.; Strange, M.; Thygesen, K. S.; Vegge, T.; Vilhelmsen, L.; Walter, M.; Zeng, Z.; Jacobsen, K. W. The Atomic Simulation Environment-A Python Library for Working with Atoms. J. Phys.: Condens. Matter 2017, 29, 273002.

(56) Bernstein, N.; Csanyi, G.; Kermode, J. Quippy. https://libatoms. github.io/QUIP/.

(57) Stokes, H. T.; Hatch, D. M. FINDSYM: program for identifying the space-group symmetry of a crystal. J. Appl. Crystallogr. 2005, 38, $237-238$.

(58) Smirnova, O. A.; Avdeev, M.; Nalbandyan, V. B.; Kharton, V. V.; Marques, F. M. B. First Observation of the Reversible O3↔P2 Phase Transition Crystal Structure of the Quenched High-Temperature Phase $\mathrm{Na}_{0.74} \mathrm{Ni}_{0.58} \mathrm{Sb}_{0.42} \mathrm{O}_{2}$. Mater. Res. Bull. 2006, 41, 1056-1062.

(59) Lu, X.; Wang, Y.; Liu, P.; Gu, L.; Hu, Y. S.; Li, H.; Demopoulos, G. P.; Chen, L. Direct Imaging of Layered O3- and P2$\mathrm{Na}_{x} \mathrm{Fe}_{1 / 2} \mathrm{Mn}_{1 / 2} \mathrm{O}_{2}$ Structures at the Atomic Scale. Phys. Chem. Chem. Phys. 2014, 16, 21946-21952.

(60) Xu, G. L.; Amine, R.; Xu, Y.-F.; Liu, J.; Gim, J.; Ma, T.; Ren, Y.; Sun, C.-J.; Liu, Y.; Zhang, X.; Heald, S. M.; Solhy, A.; Saadoune, I.; Mattis, W. L.; Sun, S.-G.; Chen, Z.; Amine, K. Insights into the Structural Effects of Layered Cathode Materials for High Voltage Sodium-Ion Batteries. Energy Environ. Sci. 2017, 10, 1677-1693.

(61) Seibel, E. M.; Roudebush, J. H.; Wu, H.; Huang, Q.; Ali, M. N.; Ji, H.; Cava, R. J. Structure and Magnetic Properties of the Alpha$\mathrm{NaFeO} 2$-Type Honeycomb Compound $\mathrm{Na}_{3} \mathrm{Ni}_{2} \mathrm{BiO}_{6}$. Inorg. Chem. 2013, 52, 13605-13611.

(62) Guo, S.; Liu, P.; Yu, H.; Zhu, Y.; Chen, M.; Ishida, M.; Zhou, H. A layered P2- and O3-type composite as a high-energy cathode for rechargeable sodium-ion batteries. Angew. Chem., Int. Ed. 2015, 54, 5894-5899.

(63) Boulineau, A.; Croguennec, L.; Delmas, C.; Weill, F. Structure of $\mathrm{Li}_{2} \mathrm{MnO}_{3}$ with Different Degrees of Defects. Solid State Ionics 2010, $180,1652-1659$

(64) Liu, J.; Yin, L.; Wu, L.; Bai, J.; Bak, S. M.; Yu, X.; Zhu, Y.; Yang, X. Q.; Khalifah, P. G. Quantification of Honeycomb Number-Type Stacking Faults: Application to $\mathrm{Na}_{3} \mathrm{Ni}_{2} \mathrm{BiO}_{6}$ Cathodes for Na-Ion Batteries. Inorg. Chem. 2016, 55, 8478-8492.

(65) Bianchini, F.; Fjellvåg, H.; Vajeeston, P. Nonhexagonal Na Sublattice Reconstruction in the Super-Ionic Conductor $\mathrm{Na}_{2} \mathrm{Zn}_{2} \mathrm{TeO}_{6}$ : Insights from ab initio Molecular Dynamics. J. Phys. Chem. C 2019, 123, 4654-4663.

(66) Huang, Q.; Liu, J.; Xu, S.; Wang, P.; Ivey, D. G.; Huang, B.; Wei, W. Roles of Coherent Interfaces on Electrochemical Performance of Sodium Layered Oxide Cathodes. Chem. Mater. 2018, 30, 4728-4737.

(67) Irvine, J. T. S.; Sinclair, D. C.; West, A. R. Electroceramics: Characterization by Impedance Spectroscopy. Adv. Mater. 1990, 2, 132-138.

(68) Baral, A. K.; Narayanan, S.; Ramezanipour, F.; Thangadurai, V. Evaluation of Fundamental Transport Properties of Li-Excess GarnetType $\mathrm{Li}_{5+2 x} \mathrm{La}_{3} \mathrm{Ta}_{2-x} \mathrm{Y}_{x} \mathrm{O}_{12}(x=0.25,0.5$ and 0.75$)$ Electrolytes Using AC Impedance and Dielectric Spectroscopy. Phys. Chem. Chem. Phys. 2014, 16, 11356-11365.

(69) Amores, M.; Corr, S. A.; Cussen, E. J. Synthesis and Ionic Conductivity Studies of In- and Y-Doped $\mathrm{Li}_{6} \mathrm{Hf}_{2} \mathrm{O}_{7}$ as Solid-State Electrolyte for All-Solid State Li-Ion Batteries. J. Electrochem. Soc. 2017, 164, A6395-A6400.

(70) Li, Z. Y.; Zhang, J.; Gao, R.; Zhang, H.; Zheng, L.; Hu, Z.; Liu, X. Li-Substituted Co-Free Layered P2/O3 Biphasic $\mathrm{Na}_{0.67} \mathrm{Mn}_{0.55} \mathrm{Ni}_{0.25} \mathrm{Ti}_{0.2-x} \mathrm{Li}_{x} \mathrm{O}_{2}$ as High-Rate-Capability Cathode Materials for Sodium Ion Batteries. J. Phys. Chem. C 2016, 120, 9007-9016.

(71) Mo, Y.; Ong, S. P.; Ceder, G. Insights into Diffusion Mechanisms in P2 Layered Oxide Materials by First-Principles Calculations. Chem. Mater. 2014, 26, 5208-5214.

(72) Bo, S. H.; Wang, Y.; Ceder, G. Structural and Na-Ion Conduction Characteristics of $\mathrm{Na}_{3} \mathrm{PS}_{x} \mathrm{Se}_{4-x}$. J. Mater. Chem. A 2016, 4, 9044-9053. 